\title{
Kolonialrevisionismus der Ingenieure
}

Die überwiegende Zahl der sich zum Zeitpunkt der Kriegserklärung 1914 in DSWA aufhaltenden Ingenieure und Techniker kehrte erst im Sommer 1919, und damit nach der Unterzeichnung des Versailler Friedensvertrages, nach Deutschland zurück ${ }^{1}$ - in ein Land, das seine kolonialen Besitzungen im Rahmen des Mandatssystems des Völkerbundes an die Siegermächte hatte abtreten müssen. Zugleich ging damit auch die Abwicklung des RKA einher, das in einem ersten Schritt zum Reichskolonialministerium umbenannt und personell verkleinert wurde. Mit der Auflösung dieses Ministeriums 1920 wurden die verbliebenen Aufgaben auf die neu eingerichtete KolonialZentralverwaltung im Reichsministerium für Wiederaufbau übertragen, das damit auch die Mehrzahl der nun beschäftigungslos gewordenen ehemaligen Kolonialbeamten übernahm. ${ }^{2}$ Wie später noch Gegenstand der Erläuterungen sein wird, wurde der kolonialerfahrene Regierungsbaumeister Schubert im ebenfalls 1920 gegründeten Reichsausgleichsamt beschäftigt, das sich der Bedienung und dem Ausgleich von Schulden der Vorkriegszeit widmete. ${ }^{3}$

Das Ministerium für Wiederaufbau koordinierte unter anderem die Reparationszahlungen an die Alliierten und war verantwortlich für die Abwicklung der verbliebenen Verbindlichkeiten im Zusammenhang mit dem ehemaligen Kolonialbesitz. ${ }^{4}$ Für die Beamten bedeutete dies in erster Instanz einen lediglich formalen Wechsel, da das neue Ministerium neben den Beamten auch das Gebäude des Reichskolonialministeriums in der Wilhelmstraße übernahm. Im Gegensatz zu den Veränderungen der übergeordneten Ministerien blieben für die beschäftigten Beamten koloniale Themenstellungen auch während der ersten Jahre der Weimarer Republik bestimmend. Es waren demnach die langjährigen, teils auch kolonialerfahrenen Beamten, die die Abwicklung der deutschen Schutzgebiete administrativ begleiteten. Mit der 1924 erfolgten Wiedereinrichtung der Kolonialabteilung im Auswärtigen Amt knüpfte man institutionell an den Stand vor 1907 an. Diese übernahm im April

1 Vgl. Personen-Verzeichnis (DSWA), BArchB, R 1002/2157.

2 Nöhre, Selbstverständnis der Kolonialbewegung, 1998, S. 12; vgl. zur benannten Entwicklung van Laak, Imperiale Infrastruktur, 2004, S. 203 f.

3 Vgl. Lehmann, Reichsausgleichsgesetz, 1920.

4 Vgl. Rwankote, Zielvorstellungen der Reichspolitik, 1985, S. 44-46; van Laak, Ist je ein Reich, 2003, S. 75 . 
die kolonialen Abwicklungsaufgaben vom Ministerium für Wiederaufbau. ${ }^{5}$ Revisionistische Forderungen traten nun zunehmend hinter einer möglichen Beteiligung am Mandatssystem und einer dementsprechenden Arbeit auf dem afrikanischen Kontinent zurück. ${ }^{6}$

Durchaus mit der „Kriegsschuldfrage“ vergleichbar, empfand die Weimarer Öffentlichkeit den Verlust der Kolonien als allgemeine Kränkung und Demütigung, und somit als ein Übel, das es zu revidieren galt. „Die Aussicht, die deutschen Kolonien ganz zu verlieren, hat mit Recht die öffentliche Meinung in Aufregung versetzt", konnte man diesbezüglich einer technischen Fachzeitschrift 1919 entnehmen. ${ }^{7}$ Tatsächlich wurde den Kolonialgebieten in Afrika und der Südsee nach ihrem Verlust eine öffentliche Bedeutung zugesprochen, der sie vor dem Ersten Weltkrieg entbehrten. ${ }^{8}$ Pogge von Strandmann gibt dabei zu bedenken, dass der Weimarer Revisionismus in seinem Anspruch über die Wiederherstellung des Vorkriegsstatus hinausging. ${ }^{9}$ Entsprechende revisionistische Forderungen an die Siegermächte unterließ die Reichsregierung jedoch auch vor dem Hintergrund weit drängender politischer und sozialer Probleme im Inland..$^{10}$ Dennoch bedeutete das Ende Deutschlands als Kolonialnation keinesfalls das Verschwinden jeglicher kolonialer Fantasien und Schwärmereien, wie das folgende Kapitel verdeutlicht. ${ }^{11}$

Koloniale Gesellschaften und Vereine, ihrem eigentlichen Tätigkeitsfeld nach 1919 beraubt, verlegten sich darauf, kolonial-revisionistische Forderungen zu popularisieren. Die Rolle der institutionellen,Speerspitze dieser Bewegung in der Weimarer Republik übernahm die DKG. Zwar hatte sich die Zahl ihrer Mitglieder in der Nachkriegszeit auf zirka 25.00o fast halbiert, dennoch konnte sie ihre Position als bedeutendste Organisation der kolonialen Bewegung verteidigen. Im Zuge dieser Entwicklung sah sich aber auch die bereits seit 1887 bestehende DKG zu Beginn der 192oer-Jahre mit finanziellen Problemen konfrontiert, die schließlich 1922 in die Gründung der Kolonialen Reichsarbeitsgemeinschaft (KORAG) mündeten. Dieser Gruppe oblag es, die einzelnen propagandistischen Aktivitäten auch der kleineren Untergruppen wie

$5 \quad$ Verordnung über die Regelung der kolonialen Angelegenheiten vom 21.3.1924, in: RGBl. Nr. 25, S. 371, vgl. auch die Geschäftsverteilungspläne: Kolonialverwaltung des Deutsches Reiches, S. LV-LVI, BArchB, R 1001, Anlage 3.

6 Vgl. van Laak, Imperiale Infrastruktur, S. 204.

7 Großmann, Wirtschaftliche Bedeutung, 1919, S. 210-215.

8 Dementsprechend äußerte sich auch Seitz in der Rückschau auf die deutsche Kolonialtätigkeit: Seitz, Vorwort, 1924.

9 Pogge von Strandmann, Imperialism and Revisionism, 1986, S. 92 f.

10 Linne, Deutschland jenseits, 2008, S. 18 f.; Hinnenberg, Die deutschen Bestrebungen, 1973, S. 13; van Laak, Imperiale Infrastruktur, 2004, S. 202.

11 Linne, Weiße Arbeitsführer, 2004, S. 6. 
der deutschen Kolonialvereine zu koordinieren, um keine monetären Mittel zu verschwenden. ${ }^{12}$ Die KORAG diente wenige Jahre später dem Kolonialingenieur Alfred Andreas Schubert als Vorbild für seine Idee einer Gemeinschaft kolonialaffiner Techniker und Ingenieure.

Schubert, der geistige Vater und Begründer der organisierten Kolonialtechnik, griff einige der bereits im öffentlichen Diskurs vorhandenen kolonialrevisionistischen Ideen auf, die eine gewisse Verbreitung und Akzeptanz in der Öffentlichkeit der Weimarer Republik für sich beanspruchen durften. Zudem begünstigte gerade die Abwesenheit realer Betätigungsmöglichkeiten in Afrika, samt dem Fehlen damit verbundener Negativschlagzeilen über etwaige Kolonialskandale wie auch realer Kosten für die militärische Beherrschung, für Administration oder den Ausbau der jeweiligen Infrastruktur eine positive koloniale Grundstimmung bis hin zum Ausbruch eines regelrechten Kolonialfiebers. Im Falle der organisierten Kolonialtechnik sollte diese Inkubationszeit bis zum Juni 1924 andauern. ${ }^{13}$

\subsection{Kolonialingenieure ex post}

Erst an dieser Stelle der Arbeit wird der bereits analytisch gebrauchte Begriff des Kolonialingenieurs und -technikers hinsichtlich seiner historischen Verwendung in den Quellen betrachtet. Davon ungeachtet stellt er weiterhin eine analytische Kategorie dar, um jene spezifische Gruppe der Ingenieure, die in den Kolonien tätig war, von ihren Berufskollegen, auf die solches nicht zutraf, sinnvoll zu unterscheiden. Die späte Trennung zwischen der analytischen und der historischen Dimension der Begrifflichkeit begründet sich aus dem chronologischen Vorgehen, da jener Terminus mit einer Ausnahme erst in den 1920er-Jahren in den deutschsprachigen Quellen nachweisbar ist und damit eine ex-post-Beschreibung darstellt. ${ }^{14}$ Lediglich ein Bruchteil der Techniker und Ingenieure, die mit der Vorsilbe ,kolonial-' als Mitglieder einer speziellen

12 Hildebrand, Reich zum Weltreich, 1969, S. 100 f.; Nöhre, Selbstverständnis der Kolonialbewegung, 1998, S. 33-35; Gouaffo, Wissens- und Kulturtransfer, 2007, S. 40 f.; Linne, Deutschland jenseits, 2008, S. 21 f.; Pogge von Strandmann, Imperialism and Revisionism, 1986, S. 95 .

13 Vgl. Kohlstock, Ratgeber für die Tropen, 1905, S. 3, 55; Kohlstock verweist bereits auf den ersten Seiten auf das ,Phänomen' des Kolonialskandals.

14 Vgl. Foehr, Kolonialingenieur, 1910, S. 165 f. Der Direktor des Polytechnikums in Köthen, Karl Foehr, spricht im Rahmen des Ferienkurses für Kolonialtechnik spezifisch von einem „Kolonie-Ingenieur“: Ankündigung Foehr, ca. Frühjahr 1925, Hochschularchiv Köthen (HArch-Kö), 1. Bestand Akte 27, fol. 7 . 
Berufskohorte in einer analytischen Kategorie zusammengefasst wurden, verwendete diesen Begriff auch in der Selbstbeschreibung. Historisch wird dieser Titel beziehungsweise diese Berufsbezeichnung erst nach dem Ersten Weltkrieg greifbar.

Die Auseinandersetzung mit der Genese des Begriffes, allen voran seiner inhaltlichen Zuschreibung wirft ein wichtiges Schlaglicht auf die eigentliche Konstitution wie auch die Eigenwahrnehmung jener Gruppe technischer Experten. Es ist durchaus erklärungsbedürftig, warum der Terminus Kolonialingenieur erst nach dem abrupten Ende der deutschen Kolonialherrschaft in den Quellen nachzuweisen ist. Die technischen Beamten im Kolonialdienst wurden erst dann zu Kolonialingenieuren, als sich deren genuines Betätigungsfeld außer Reichweite befand. In gut anderthalb Jahrzehnten verstärkten technischen Engagements im kolonialen Afrika hatte es keiner speziellen Titulierung bedurft. Weder in Briefen oder Memoiren der Ingenieure und Techniker noch in offiziellen Schreiben vor 1918 findet sich die Bezeichnung Kolonialingenieur. Die betroffenen technischen Akteure firmierten vielmehr als in der Kolonialabteilung des Auswärtigen Amtes beziehungsweise im RKA beschäftigte Regierungsbaumeister, Ingenieure und Techniker unter dem Zusatz des Dienstortes sowie ihrer jeweiligen Stellung aber auch als technische Kolonialbeamte. ${ }^{15}$

Die benannten Personen waren dementsprechend weniger Kolonialtechniker als vielmehr Ingenieure und Regierungsbaumeister, die sich für eine bestimmte Anzahl an Dienstperioden in den Schutzgebieten aufhielten. Die Erfahrung in den Kolonien war dabei Teil ihrer Berufsvita. Erst als ihnen die Möglichkeit dieser Betätigung versagt blieb, ergab sich für einzelne Vertreter dieser Gruppe die Notwendigkeit, sich als besondere Gemeinschaft innerhalb der Profession der Ingenieure zu formieren. ${ }^{16}$ Es ist durchaus überraschend, dass der Begriff weder im Zuge des Versailler Vertrages noch der Übergabe der deutschen Kolonien an die vom Völkerbund bestimmten Mandatsmächte aufkam, sondern erst ein halbes Jahrzehnt später im Fahrwasser der Diskussionen um den Dawes-Plan sowie der deutschen Reparationszahlungen. Erstmals wird der Ausdruck ,Kolonialtechniker' oder ,Kolonialingenieur' öffentlich in einer Annonce aus dem Jahr 1924 in diesem Sinne gebraucht, wie auch der

\footnotetext{
15 Vgl. dazu u. a. ZdB, Verzeichnis der im preußischen Staate und bei Behörden des deutschen Reiches angestellten Baubeamten, Jg. 1904-1918; Tesch, Laufbahn, 1902.

16 Vgl. Schubert, Koloniale Aufgabe, 1927, S. 19.
} 
Oberbegriff der ,Kolonialtechnik‘ als Beschreibung eines genuinen eigenständigen Technikbereichs. ${ }^{17}$

Zurückzuführen ist diese Wortschöpfung wohl auf eine Entlehnung aus dem französischen oder englischen Sprachgebrauch durch die AKOTECH und hier sehr wahrscheinlich auf ihren Mitbegründer, den Regierungsbaumeister im Reichsausgleichsamt Alfred Andreas Schubert. ${ }^{18}$ Er veröffentlichte auch die zuvor erwähnte Annonce. Sämtliche Verwendungen dieser oder ähnlicher Begrifflichkeiten in den 1920er-Jahren finden sich ausschließlich innerhalb oder im Umfeld der Arbeitsgemeinschaft, die die Kolonialtechnik bereits im Namen trug. Dieser Umstand kann nur wenig verwundern, da es sich bei den Gründern der AKOTECH um sechs Regierungsbaumeister und DiplomIngenieure handelte, von denen allein vier - Baltzer, Fischer, Allmaras und Schubert - bereits vor dem Krieg in der für technische Aufgaben zuständigen Abteilung B im RKA zusammengearbeitet hatten. Die beiden Regierungsbaumeister Rintelen und Reh konnten ebenfalls auf mehrere Jahre an kolonialer Berufserfahrung in DSWA zurückblicken. ${ }^{19}$ In den frühen 193oer-Jahren setzte sich der Begriff der ,Kolonialtechnik' dann auch in den Äußerungen von Regierungsmitgliedern durch, die sich am kolonialtechnischen Diskurs beteiligten. ${ }^{20}$

Die Hauptaufgabe, der sich die AKOTECH seit ihrer Gründung verschrieben hatte und die sie auch bis in die 193oer-Jahre proklamierte, war die Sammlung und Sicherung kolonialtechnischen Wissens: ${ }^{21}$

Wohl verfügen wir noch über eine Reihe in langjähriger Kolonialarbeit geschulter Kräfte. Sie werden aber von Tag zu Tag älter. Ihre Erfahrungen nehmen sie mit ins Grab. Gar mancher von ihnen würde gerne sein Wissen zur Verfügung stellen, aber es fehlt ihm an Zeit, es niederzulegen. ${ }^{22}$

17 Zeitungsannonce, September 1924, BArchB, R 8023/377, fol. 189; Baltzer, Technische Großtaten, 1924, S. 163 f.

18 Der Begriff des „colonial engineer“ als eigenständige Bezeichnung ist bereits in der ersten Ausgabe der Colonial Office List von 1888 nachzuweisen, so zum Beispiel für das Public Works Departement der Kolonie Natal (S. 177).

19 Vgl. eigene Darstellung nach: ZdB, Verzeichnis der im preußischen Staate und bei Behörden des deutschen Reiches angestellten Baubeamten, für die Jahrgänge: 1898-1918; Beschlüsse Auslands- und Kolonialtechniker, 17.9.1924, BArchB, R 8023/377, fol. 202 f.

$20 \quad$ Vgl. Kapitel 4.3 Kolonialtechnik im Nationalsozialismus.

21 Vgl. Zeitungs-Annonce, September 1924, BArchB, R 8023/377, fol. 189. Die AKOTECH war propagandistisch äußerst umtriebig, vor allem in Bezug auf die Unterstützung kolonialrevisionistischer Positionen: van Laak, Im Tropenfieber, 2010, S. 93; vgl. hierzu auch die erste Ausgabe der Zeitschrift der Arbeitsgemeinschaft: Anonymus, Ziele der Akotech, 1925 .

Auszug aus Der Kolonialdeutsche, ca. 1924, BArchB, R 10o1/6738, fol. 181. 
Bereits 1925 hatte die Schriftleitung der Mitteilungen der Vereinszeitschrift der AKOTECH auf die Schwierigkeit dieser Sammlungsarbeit hingewiesen, da einige Kolonialingenieure bereits verstorben waren. ${ }^{23}$ Die Erfahrungen der alten deutschen Kolonialingenieure sollten um die neuesten Erkenntnisse der anderen Kolonialmächte erweitert und auf dem aktuellsten Stand gehalten werden.

Mit einiger Berechtigung ließe sich mit Blick auf die von der AKOTECH verfolgte Politik von einer Doppelstrategie sprechen: Zum einen wurde von der Einmaligkeit der kolonialen Umgebung auf die Besonderheit der dort gemachten Erfahrungen geschlossen und zum anderen dienten diese als gemeinsamer Bezugs- und Erinnerungsrahmen für die Kolonialingenieure, der auf die Bildung einer exklusiven Gruppenidentität abzielte:

Die Erschließung der Kolonien in wirtschaftlicher und kultureller Beziehung war mit ein Werk der Technik. Schwierigkeiten des Klimas und der örtlichen Verhältnisse sowie der Mangel an gelernten Arbeitern, unterscheiden die technischen Arbeitsmethoden in den Tropen ganz wesentlich von denen der Heimat. Darum hat sich im Laufe der 40 jährigen Kolonialtätigkeit eine besondere Kolonialtechnik entwickelt, mit der aber ein nur verhältnismäßig kleiner Kreis von Ingenieuren vertraut ist. ${ }^{24}$

Ganz in diesem Sinne war bereits Anfang des 20. Jahrhunderts am Friedrichs Polytechnikum in Köthen ein „Kursus für koloniale Technik“ abgehalten worden, der sich an „technisch gebildete Hülfskräfte [sic!], Betriebsingenieure“ richtete, die in kolonialen wie tropischen Gebieten tätig werden wollten. Direktor Foehr hatte in diesem Zusammenhang jedoch gerade nicht von einer eigenständigen Kolonialtechnik gesprochen. ${ }^{25}$

Für die Jahre 1924 und 1925 sowie für die Zeit ab 1930 lassen sich immer wieder rhetorische Versuche vonseiten bestimmter AKOTECH-Mitglieder nachweisen, den Kolonialingenieur zu definieren und ihn damit von anderen Fachingenieuren abzugrenzen. Besonders engagiert zeigte sich dabei der Techniker und Tropenlandwirt Erich Köthe. Er hatte mehr als ein Jahrzehnt in DOA verbracht und war in den 193oer-Jahren ein umtriebiger Ingenieur im Bereich der kolonialen Propaganda. Zum Ende des Jahrzehnts sollte er in der Schriftenreihe über die Kolonial- und Tropentechnik einen Band zur maschinellen Aufbereitung von tropischen Rohstoffen veröffentlichen, was

\footnotetext{
23 Anonymus, Übersicht über die bisherige Tätigkeit, 1925.

24 Beschluss Auslands- und Kolonialtechniker, 17.9.1924, BArchB, R 8023/377, fol. 204 f.

25 Antrag Direktor Foehr, HArch-Kö, 1. Bestand Akte 27, fol. 5; vgl. darüber hinaus Städtisches Friedrichs-Polytechnikum, Ferienkursus für koloniale Technik, 1905; ebda., Ferienkursus für koloniale Technik, 19o6; ebda., Ferienkursus für koloniale Technik, 1908.
} 
jedoch aufgrund des Krieges unterblieb. In der Ankündigung seines Bandes war er bereits als Tropeningenieur bezeichnet worden. Auch in einem Vortrag über die Deutsche Ingenieurarbeit in Afrika „bestätigt er [Köthe, S. B.] unsere bekannte Erfahrung dahingehend, dass der Auslandsingenieur ein Ingenieur eigener Prägung sein muß." Im Gegensatz zu einem vor allem theoretisch gebildeten Ingenieur sollte jener „nämlich die praktischen Kenntnisse eines Monteurs vereinigen mit einem möglichst breiten technologischen Wissen eines theoretisch gut durchgebildeten Ingenieurs, und dabei auch ein findiger Konstrukteur sein. ${ }^{.26}$

Trotz der Versuche, den Kolonialingenieur durch eine umfassende Definition und Beschreibung in der Retrospektive als eigene Ingenieursgruppe zu konstruieren, zeigten sich bereits früh Ungenauigkeiten bei der trennscharfen Verwendung verwandter Begriffe wie Kolonial-, Tropen- oder Auslandsingenieur. ${ }^{27}$ Schubert schrieb beispielsweise im Titel über die Ausbildung von Kolonialtechnikern, um im entsprechenden Artikel ausschließlich den Begriff ,Auslandstechniker' zu gebrauchen. Seine Beschreibung stimmt mit der Köthes überein, wobei er diese noch um die Notwendigkeit eines weitreichenden volkswirtschaftlichen Verständnisses erweitert. ${ }^{28}$ Dennoch wird in den verschiedenen Ausführungen deutlich, dass für die koloniale Arbeit keine auf isolierten Fachgebieten spezialisierten Experten gefragt waren, sondern vielseitige Praktiker - „ein Universalingenieur"29 -, die ein breites Wissen mit handwerklichem Geschick und einem ausgesprochenen Improvisationsvermögen verbanden. ${ }^{30}$ Der Ingenieur Müller, der selbst einige Zeit in Afrika verbracht hatte, hob zusätzlich Geduld als besondere Tugend hervor, die aufgebracht werden müsse, da viele der aus dem westafrikanischen Hinterland stammenden Arbeiter mit europäischen Werkzeugen nichts anzufangen wüssten und einer dementsprechenden Einarbeitung bedürften. ${ }^{31}$

26 Anonymus, Deutsche Ingenieurarbeit in Afrika, 1932, S. 5. Schon Ende des 19. Jahrhunderts hatte Bernhard auf ganz ähnliche umfassende praktische und theoretische Kenntnisse als Voraussetzungen für den Kolonialbahnbau verwiesen: Bernhard, Eisenbahnbau in Deutsch-Ostafrika, 1898, S. 133.

27 Weniger häufig findet sich der Begriff des Exportingenieurs, der sich jedoch fast ausschließlich auf Techniker bezieht, die für deutsche Firmen im Ausland im Vertrieb tätig waren.

28 Schubert, Ausbildung von Kolonialtechnikern, 1925, S. 11.

29 Röhlke, Ausbildung und Fortbildung, 1938, S. 300.

30 Vgl. Baltzer, Technik, 1924, S.167. Ähnliches weist Pesek im Hinblick auf Wissmann nach, der ebenjene Vielseitigkeit von seinen Offizieren in DOA forderte: Pesek, Ende eines Kolonialreiches, 2010, S. 342.

31 Müller, Technische Streifzüge, 1925, S. 17. 
Neben derVielzahl an Fertigkeiten und einem breiten praktisch-technischen Wissensbestand verlangten die speziellen kolonialen Verhältnisse sowie die aufwendigen und langen Kommunikationswege einen Kolonialingenieur, „der in der Lage ist, auch in schwierigen Fällen selbständig Entscheidungen zu treffen.“32 Laut Marine Baurat a. D. Röhlke, ebenfalls führendes Mitglied der AKOTECH, war hierfür aber auch „eine selbständige Stellung“ für den Ingenieur vonnöten, damit dieser "ohne kleinlich Behinderung frei schaffen“ könne. ${ }^{33}$

Eine einheitliche Sprachregelung ließ sich demnach auch in den Reihen der organisierten Kolonialtechniker nicht finden. Einen diesbezüglichen Versuch der Kategorisierung unternahm Stritzel 1930, der im Rahmen der zweiten Überseewoche an der TH Hannover in einem Vortrag eine Dreiteilung der Länder und Gebiete der Erde annahm. Unterschieden nach ihrem jeweiligen Entwicklungsstand ergaben sich hieraus ganz verschiedene An- und Herausforderungen für den betroffenen Ingenieur. „Besonders verlockend ist natürlich für jeden Auslandsingenieur die Pioniertätigkeit in völlig unterentwickelten Ländern“, konstatierte er und bezog sich damit auf die kolonialen Gebiete in Afrika, ohne aber in diesem Zusammenhang den Begriff des Kolonialingenieurs zu verwenden. ${ }^{34}$ Auch Georg Sinner bevorzugte in seinen Ausführungen Bezeichnungen wie „Exotische[] Technik“, die sich aber auf einen ganz ähnlichen Anwendungskreis wie die koloniale Technik bezogen. ${ }^{35}$

Neben dieser Melange unterschiedlicher Begriffe und Titel gab es jedoch auch Stimmen wie die Karl Krügers, der 1939 die Existenz eines eigenständigen kolonialtechnischen Experten negierte: Es könne „keinen ,Kolonialtechniker an sich geben [...], sondern nur Fachingenieure, die für den Dienst in fremden Ländern zusätzliche Kenntnisse und Erfahrungen gesammelt haben". ${ }^{36}$ Die koloniale Sendungsidee der Technik stritt jedoch auch er keineswegs ab, tradierte sie vielmehr in die Zeit nach dem Zweiten Weltkrieg. ${ }^{37}$ Mit seiner Aussage orientierte er sich stark am Standpunkt Röhlkes. Ein Jahr zuvor hatte er den Kolonialingenieur eben auch nicht als „eine neue Art von SpezialIngenieur“ verstanden, sondern als „einen Ingenieur einer vorhandenen Fachrichtung“, der jedoch eine Tätigkeit in den Kolonien anstrebe, wobei aber auch Röhlke auf die „für diesen Zweck nötigen zusätzlichen Kenntnisse“ hinwies. ${ }^{38}$

\footnotetext{
32 Röhlke, Ausbildung und Fortbildung, 1938, S. 300.

33 Röhlke, Institut für Kolonial- und Tropentechnik, 1938.

34 Stritzel, Tätigkeit des Ingenieurs, 1930, S. 199 f.

35 Vgl. dazu Sinner, Gefährdetes Europa, 1932, S. 88-100.

$36 \quad$ Krüger, Tropentechnik, 1939, S. 7.

37 van Laak, Imperiale Infrastruktur, 2004, S. 393-402.

38 Röhlke, Institut für Kolonial- und Tropentechnik, 1938, S. 73 [Herv. i. O.].
} 
Krügers Aussagen müssen mit Blick auf den Titel seiner Veröffentlichung jedoch relativiert werden, denn zumindest die Tropentechnik als eigenständigen Fachbereich lehnte er keineswegs ab. ${ }^{39}$

Neben der benötigten fachlichen und persönlichen Eignung forderte der Regierungsbaumeister Schubert von den Kandidaten weitere Fähigkeiten. Mit Blick auf die Anstrengungen, Entbehrungen und Gefahren in den tropischen Kolonien verlangte er von den angehenden Kolonialingenieuren die Bereitschaft, „,ihr Leben für das große deutsche Vaterland zu opfern“ ${ }^{40}$ Eine Idee, die auch der ehemalige Chefredakteur der $D O Z$, Heinrich Pfeiffer, Jahre später aufgriff, wenn er sich an die „opferfreudigen Ingenieure“ beim Bau der TanganjikaBahn erinnerte. ${ }^{41}$ Damit setzten die beiden Autoren die Arbeit in den Kolonien mit der Aufopferungsbereitschaft in Bezug, wie sie eingangs als typisches Merkmal des Feldes der Technik geschildert wurde. Im kolonialen Kontext wirkte diese Verknüpfung überzeugender als beim alltäglichen technischen Arbeiten in Deutschland. ${ }^{42}$

Die Breite der angeführten Definitionsversuche verdeutlicht, dass es sich beim Kolonialingenieur letztendlich um eine Kategorisierung in Bezug auf das primäre Tätigkeitsfeld beziehungsweise den Arbeitsort handelte. Krügers kritischen Ausführungen ist insofern beizupflichten, als es sich bei den Kolonialingenieuren selbstverständlich um Fachingenieure und Techniker handelte, deren verbindendes Element ein mehr oder minder langer Aufenthalt in den deutschen Schutzgebieten war. Die Tatsache, dass die persönliche Identifikation mit der kolonialen Tätigkeit erst im Zuge ihrer zum Teil erzwungenen Rückkehr ins Deutsche Reich hervortrat, ist dabei weniger fragwürdig als vielmehr identitätsstiftend zu verstehen. Erst als diese Gruppe von Ingenieuren gezwungen war, sich wieder in die Arbeits- und Alltagswelt des Mutterlandes zu integrieren, traten spezifische Unterschiede deutlicher hervor. So war es wieder einmal Schubert, der die besondere Bedeutung der Kolonialingenieure Mitte der 1920er-Jahre herausstellte:

Wollen wir unser Volk wieder hochbringen, dann müssen wir alle Vorkehrungen treffen, um jederzeit bereit zu sein, neue Auslands- und Kolonialaufgaben zu übernehmen. Dazu brauchen wir Männer, die das erforderliche fachtechnische Wissen und Können besitzen [...]. ${ }^{43}$

39 Siehe dazu u. a. Krüger, Tropentechnik, 1939.

40 Schubert, Technik in den deutschen Schutzgebieten, 1926, S. 139.

41 Pfeiffer, Bwana Gazetti, 1933, S. 97; vgl. für die spezifischen Probleme und Herausforderungen beim Abstecken der Eisenbahntrasse und dem nachfolgenden Bau die Ausführungen in Kapitel 3.1.

42 Vgl. dazu auch Beese, Heroen, 2019.

43 Schubert, Technik in den deutschen Schutzgebieten, 1926, S. 139. 
An diesen „Helden wird es uns nicht fehlen“, war der Regierungsbaumeister überzeugt und sah darin den Schlüssel zu Deutschlands zukünftiger Stärke. Schubert war sich sicher, auf „Wissen und Können [...] gründet sich künftig unsere Macht." Dafür nahm er seine Kollegen mit ähnlicher Berufsvita in die Pflicht: „Darum dürfen wir alten Kolonialleute nicht ruhen und rasten, sondern müssen unsere Erfahrungen dem kommenden Geschlecht preisgeben“. ${ }^{44}$ Einen ähnlich hohen Stellenwert wie die Bewahrung und Tradierung spezifisch kolonialtechnischer Wissensbestände hatte für Schubert daher auch die Popularisierung der Kolonialtechnik für eine interessierte Öffentlichkeit. Dementsprechend finden sich immer wieder populärwissenschaftlich gehaltene Artikel über die Eisenbahnen oder andere Kunstbauten in den Kolonien, wie im gerade zitierten Deutschen Kolonialbuch, die sich an ein breites nichttechnisches Publikum richteten und damit die Kategorie der kolonialen Technik samt ihren Akteuren, den Kolonialingenieuren, bekannt zu machen suchten.

Vor dem Hintergrund der in Kapitel 3.5 ausgeführten hierarchischen Ordnung kann es durchaus verwundern, dass der Kolonialingenieur als einheitliche Gruppenbezeichnung die inneren Unterschiede hinsichtlich Ausbildung und Stellung nivellierte. Die AKOTECH sprach alle technischen Kräfte an: „vom Handwerker und Werkmeister aufwärts bis zum Leiter eines großen technischen Betriebes". ${ }^{45}$ Dies darf vor dem Hintergrund der überschaubaren Zahl von Ingenieuren und Technikern mit kolonialer Erfahrung nicht erstaunen. ${ }^{46}$ Vorstand und Wortführer der Arbeitsgemeinschaft rekrutierten sich jedoch mit einer Ausnahme ausschließlich aus den Reihen der Regierungsbaumeister und Diplom-Ingenieure und damit aus dem Kreis der akademisch gebildeten technischen Elite. Nach außen gab man sich also ein bewusst egalitäres Image, wobei fraglich bleibt, inwieweit die hierarchischen Unterschiede innerhalb der Ingenieursgruppe Außenstehenden bekannt waren. Die interne hierarchische Struktur der AKOTECH ähnelte jedoch stark den Machtbeziehungen, wie sie für das Feld der Technik beschrieben wurden.

Mit Bourdieu ließe sich dieses Verhalten, die Gründung einer kolonialtechnischen Ingenieursvereinigung, im Sinne einer Akkumulation von symbolischem Kapital verstehen. Die Arbeit der Ingenieure wurde im Nachhinein als kulturschaffend gewürdigt und als Erfüllung einer civilizing

44 Schubert, Technik in den deutschen Schutzgebieten, 1926, S. 139.

45 Verlohr, Zum Geleit, 1925, S. 1.

46 Nach eigenen Angaben waren bis 1925 mehr als 1oo Personen der AKOTECH beigetreten: Jahresbericht der Akotech (Arbeitsgemeinschaft für Auslands- und Kolonialtechnik), 1925/26; Berlin 1926, S. 4. 
mission propagiert, wobei die wirtschaftliche Erschließung und technische Durchdringung der kolonialen Gebiete das Ziel darstellte. ${ }^{47}$ Gerade im Hinblick auf eine in der Bevölkerung als ungerecht wahrgenommene Negierung der deutschen „Kolonisationsfähigkeit“ durch die Alliierten konnten die Ingenieure ihr Handeln in ein besseres Licht rücken. Nachträglich bot sich ihnen die Möglichkeit, ihr soziales Kapital im Sinne des Bezugs auf ein Netzwerk von kolonialtätigen Technikern zu aktivieren und damit die Möglichkeit zu vergrößern, ihr kulturelles Kapital in symbolisches umzuwandeln.

Letztendlich kann dies auch im Licht des Versuchs der Machtausweitung der technischen Intelligenz verstanden werden. Dementsprechend wundert es kaum, dass sich die AKOTECH anfangs organisatorisch einem Verein wie dem RDT anschloss, der in seinen Veröffentlichungen ungeniert technokratischen Machtfantasien huldigte. ${ }^{48}$ Diesbezüglich erscheint es geradezu folgerichtig, dass sich die Vertreter der Kolonialtechnik erst institutionell zusammenschlossen, als die Möglichkeiten zur praktischen kolonialtechnischen Arbeit schwanden. ${ }^{49}$ Thesen, Wünsche und vermeintlich einfache Lösungen für gegenwärtige Probleme konnten auf die Kolonien und hier besonders auf die diesbezügliche Rolle der Technik projiziert werden. Da den deutschen Ingenieuren die Arbeit in den Schutzgebieten verwehrt war, hatten sie auf absehbare Zeit weder die Möglich- noch die Notwendigkeit, den Beweis der Richtigkeit der eigenen Schlussfolgerungen und Versprechen anzutreten.

Besonders die Kolonialgebiete auf dem afrikanischen Kontinent erklärte man nach dem Ersten Weltkrieg zuerst zur Bedingung für Deutschlands Wiedererstarken und später $\mathrm{zu}$ einem europäischen Friedensprojekt. ${ }^{50}$ Ein europäischer Staatenverbund müsste, wie Schubert betonte, „um seine Zukunft zu sichern“, Afrika gemeinsam erschließen. ${ }^{51}$ Ohne die Heranziehung von fähigen Technikern und Ingenieuren sei dieses Ziel aber nicht zu erreichen, besonders prädestiniert für diese Aufgabe waren natürlich solche Akteure, die bereits koloniale Erfahrung vorweisen konnten. Dank dieser argumentativen Verknüpfung stilisierten sich die Akteure und mit diesen auch

47 Fuhrmann spricht von einer „technokratischen mission civilisatrice“: Fuhrmann, Bagdadbahn, 2013, S. 198 f.; vgl. u. a. Orenstein \& Koppel, Denkschrift, 1913, S. 119; Obst, Technik muss, 1939, S. 1 f.; Schubert, Technik in den deutschen Schutzgebieten, 1926, S. 132; Jefferson, Civilizing Rails, 1928.

48 Zu den kolonialen Planungsfantasien, vgl. u. a. Wagner, Stadtplanung, 2016, S. 7 o.

49 Ähnlich dazu auch das Feld der Kolonialgeografie: Gräbel, Erforschung der Kolonien, 2015, S. 78 .

$5^{\circ}$ Anonymus, Vortrag von Herrn Schoenheit (1924), 1925; Schubert, Technische Pionierleistungen, 1938, S. 1; Obst, Technik muss, 1939; Remy, Internationale Ziele, 1941, S. 71.

$5^{1} \quad$ Schubert, Rettung Europas, 1929, S. 6 [Herv. i. O.]; vgl. zu diesem Bedrohungsszenario für Europa auch Sinner, Gefährdetes Europa, 1932. 
die Kolonialtechnik zu Rettern Deutschlands und sogar Europas. Somit wurde zugleich ihre Arbeit in Afrika vor 1914 ex post zu „Pionierleistungen“ stilisiert, mit der sie einen beträchtlichen Teil zur Rettung Europas beigetragen hatten. ${ }^{2}$ Als Sprachrohr dieser Überzeugung gerierte sich frühzeitig die AKOTECH.

\subsection{Arbeitsgemeinschaft für Kolonial- und Tropentechnik}

Die Initiative zur Gründung einer Organisation, die gezielt die Belange der Kolonialingenieure vertreten sollte, ging auf den Regierungsbaumeister Alfred Andreas Schubert zurück. Wie bereits erwähnt, war Schubert selbst über Jahre hinweg in DSWA beim Eisenbahnbau tätig gewesen. Nach seinem Ausscheiden aus dem unmittelbaren Kolonialdienst hatte er 1912 eine etatmäßige Stelle im RKA in Berlin angetreten, die er bis zum Ersten Weltkrieg bekleiden sollte, unterbrochen nur von einer Expedition in die portugiesische Kolonie Angola. ${ }^{53}$

Ausgangspunkt dieser Entwicklung war die Jahrestagung des RDT in Bernburg im Juni 1924. Beim RDT handelte es sich um eine berufsständische Vereinigung der Techniker und Ingenieure, die neben der Steigerung der gesellschaftlichen Reputation der technischen Profession immer wieder auch technokratische Positionen hinsichtlich des politischen Systems vertrat und eine der Bedeutung der Technik angemessene Repräsentation ihrer Berufsgruppe in den Parlamenten und Regierungen forderte. ${ }^{54}$ Die Übereinstimmung mit Positionen, die später von Akteuren der organisierten Kolonialtechnik vertreten werden sollten, zeigte sich dabei deutlich. Auch die Ideologie der Erschließung, wie sie an entsprechender Stelle erläutert wurde, war im Grunde eine technokratische Idee der räumlichen und sozialen Umgestaltung mit Mitteln der Technik im Sinne vermeintlich objektiver Parameter und Zielvorstellungen. Auf der Tagung in Bernburg verband Schubert beide Bereiche. Er pries die Arbeit in den Kolonien emphatisch als „ein vom Parteigeist unberührtes Streben nach Schaffung eines großen deutschen Vaterlandes! “55 Wahrscheinlich im Zuge seines Vortrages auf der Jahresversammlung des RDT wandte sich Schubert auch an die KORAG, um erstmals für seine Idee einer eigenständigen technischen Kolonial-Reichsarbeitsgemeinschaft (TEKORAG)

$5^{2}$ Schubert, Technische Pionierleistungen, 1938; Schubert, Rettung Europas, 1929.

53 Vgl. RKA an Hauptkasse (DSWA), 7.2.1912, BArchB, R 1002/1576, fol. 1; RKA an Gouvernement (DSWA), 13.2.1912, ebda., fol. 3; Schubert, Technik in den deutschen Schutzgebieten, 1926, S. 511 (Anhang).

54 Vgl. Willeke, Technokratiebewegung, 1995, S. 147-151.

55 Schubert, Koloniale Aufgabe, 1927, S. 19. 
zu werben. ${ }^{56}$ Der verantwortliche Geheimrat Theodor Gunzert beschied Schubert, dass die Zeit für solch eine Institution noch nicht gekommen sei. Der Regierungsbaumeister ließ sich von seinem Unterfangen jedoch nicht abbringen. ${ }^{57}$

Das Aufgabenspektrum der TEKORAG sollte das regelmäßige Sichten und Sammeln von Informationen fremder Kolonialmächte hinsichtlich Technikeinsatz und Erschließungsstand umfassen. Auf dieser Basis gelte es dann, Vorbereitungen zu einem planmäßigen Vorgehen für eine erneute deutsche Kolonialherrschaft zu treffen. Diese Arbeiten müssten auch das Aufstellen einer Rangliste beinhalten, mit deren Hilfe es möglich sei, die Bau- und Unterhaltskosten verschiedener Verkehrsmittel für die einzelnen Kolonialgebiete gegeneinander abzuwägen. Auf diesen Vorarbeiten würden dann auch die technischen Schulungen der zukünftigen Kolonialbeamten fußen, für deren Erfolg Schubert wiederholt die Bedeutung in der kolonialen Praxis erfahrener Kolonialingenieure hervorhob. ${ }^{58}$ Es ist anzunehmen, dass Schubert seine Schreiben mit Blick auf den am 17. und 18. September 1924 in Berlin stattfindenden "erste[n] Nachkriegs-Kolonialkongreß“ verfasste, der symbolisch für die neuerliche Kolonialeuphorie des Jahres 1924 - dem vierzigjährigen Jubiläum der ersten deutschen Kolonialerwerbung - stand und damit ebenfalls eine bedeutende Rolle für die Gründung der Arbeitsgemeinschaft als erster Vereinigung kolonialerfahrener, technischer Experten spielte. ${ }^{59}$

In einer Ende September des gleichen Jahres veröffentlichten Zeitungsannonce beschrieb Schubert diesen institutionellen Zusammenschluss als notwendig, ,nicht um auch zu reden, sondern um die Erfahrungen der Kolonialtechniker zu erhalten. ${ }^{“ 60}$ Vorangegangen waren Beschwerden vonseiten der Techniker und Ingenieure über eine fehlende Beteiligung und Beachtung der eigenen Profession auf dem Kolonialkongress. ${ }^{61}$ Die maßgeblich an der Zusammenkunft beteiligte DKG wies diese Anschuldigungen umgehend mit der Bemerkung zurück, dass es eine öffentliche Ausschreibung für die Veranstaltung gegeben hatte, auf die sich auch die technischen Kreise hätten bewerben können. Um solche Unstimmigkeiten künftig zu vermeiden, legte

\footnotetext{
$5^{6}$ Schubert an KORAG, Juni 1924, BArchB, R 1001/6738, fol. 7 .

57 Schubert an KA AA, 15.8.1924, ebda., fol. 14.

58 Vgl. Schubert an KORAG, Juni 1924, ebda., fol. $8 \mathrm{f}$.

59 Deutscher Kolonialkongreß, Verhandlungen des Deutschen Kolonialkongresses, 1924; Rwankote, Zielvorstellungen der Reichspolitik, 1985, S. 57; Seitz, Vorwort, 1924; Pogge von Strandmann, Imperialism and Revisionism, 1986, S. 97.

6o Zeitungs-Annonce, September 1924, BArchB, R 8023/377, fol. 189 .

61 Reichsbund der höheren Technischen Beamten an DKG, 25.9.1924, ebda., fol. 188.
} 
man dem RDT den Beitritt zur KORAG nahe. ${ }^{62}$ Zumindest die wenig später gegründete AKOTECH sollte diesen Schritt im Oktober des Jahres schließlich vollziehen. ${ }^{63}$

Hervorgegangen war die Arbeitsgemeinschaft aus einem eigens einberufenen Treffen am Rande des Kolonialkongresses 1924, zu dem die Geschäftsleitung des RDT ihre Mitglieder in der eigenen Verbandszeitschrift Deutsche Technische Warte ${ }^{64}$ eingeladen hatte. ${ }^{65}$ Dieses konstituierende Treffen der „versammelten Auslands- und Kolonialtechniker“ fand am 17. September 1924 im Vereinshaus des VDI statt. Den Äußerungen des RDT-Bundesvorsitzenden Karl Strecker zufolge beschlossen die knapp 100 anwesenden Ingenieure die Gründung der AKOTECH und fassten erste programmatische Beschlüsse. Die kolonial-revisionistische Grundausrichtung der Arbeitsgemeinschaft leitete sich aus ihrer Argumentation ab, dass eine Erfüllung der im DawesPlan beschlossenen Forderungen nur durch die Wiedererlangung der Schutzgebiete sowie ihrer sofortigen und effektiven Ausnutzung gelingen könne. ${ }^{66}$ Diesen Grundsatz betonten die Mitglieder der AKOTECH auch in ihrer ersten regulären Sitzung, die bereits eine Woche nach der Gründung stattfand. Mit dem Ziel, Vorarbeiten für eine effiziente und kostengünstige verkehrstechnische Erschließung der Kolonien und damit auch ihrer wirtschaftlichen und strategischen Potenziale voranzutreiben, orientierte man sich deutlich an Schuberts Idee der TEKORAG. Neben Berichten gegenwärtiger Kolonialmächte wollte man dafür vor allem auf die Erfahrungen der deutschen Kolonialingenieure zurückgreifen. ${ }^{67}$

Die Haltung der DKG machte deutlich, dass Schubert mit der Gründung der AKOTECH durchaus einen Nerv in der Kolonialbewegung der Weimarer Republik traf. ${ }^{68}$ Die Gesellschaft brachte der kolonialen Ingenieursver-

62 Antwortschreiben DKG, 27.9.1924, BArchB, R 8023/377, fol. 187.

63 AKOTECH an KORAG, 19.10.1924, ebda., fol. $212 \mathrm{f}$.

64 Die Zeitschrift des RDT erschien lediglich in den Jahren 1924 und 1925 unter dieser Bezeichnung, ansonsten firmierte sie unter dem Schlachtruf und Titel Technikvoran!

65 Anonymus, Aufruf, 1924; Strecker, Tätigkeit des Reichsbundes deutscher Technik, 1924, S. 26 of.

66 Beschlüsse Auslands- und Kolonialtechniker, 17.9.1924, BArchB, R 8023/377, fol. 202 f.; Strecker, Tätigkeit des Reichsbundes deutscher Technik, 1924, S. 26o f. Gerade in den Ausführungen des RDT verwiesen die Autoren häufig auf die Bedeutung des verbandseigenen „Ausschuss[es] für Auslandsfragen“, dem auch Schubert angehörte: Anonymus, Aufbau des RDT, 1924, S. 3.

67 1. AKOTECH-Sitzung, 26.9.1924, BArchB, R 8023/377, fol. 207, 209; Beschlüsse Auslandsund Kolonialtechniker, 17.9.1924, ebda., fol. $204 \mathrm{f}$.

68 Vgl. dazu auch die wohlwollende Haltung Stresemanns gegenüber der AKOTECH als privater Initiative und einer kleinen finanziellen Unterstützung: Abteilung IIIa an Büro Stresemanns, 16.1.1925, BArchB, R 1001/6738, fol. 75 f. 
einigung sowie deren Tätigkeitsfeld offen Sympathien entgegen. Auf Anfrage der Abteilung für koloniale Angelegenheiten im Auswärtigen Amt äußerte die DKG nicht nur Verständnis für die Gründung, ,da die Entwicklung in unseren Schutzgebieten und in den fremden Kolonien auch in technischer Beziehung einer dauernden Überwachung unsererseits bedarf", sondern beschloss vielmehr, „dieser Frage erhöhte Aufmerksamkeit zuzuwenden“. ${ }^{69}$ Der Vorsitzende der DKG, der ehemalige Gouverneur Kameruns und DSWA, Theodor Seitz, plante gar, eine eigenständige Kommission mit der Sammlung kolonialtechnischen Wissens zu betrauen, der auch Regierungsbaumeister Schubert angehören sollte. Das Auswärtige Amt wollte seinerseits dieses Unterfangen mit der Bereitstellung von ausländischer Literatur unterstützen. ${ }^{70}$

Schuberts vorgetragenes Anliegen, einen Ingenieur unter Vorwand in die afrikanischen Kolonien zu entsenden, um diesem die Prüfung des dortigen Technikeinsatzes zu ermöglichen, lehnte man in Berlin jedoch ab. Aus Sicht des Auswärtigen Amtes gäbe es derzeit keine Anzeichen dafür, dass Deutschland auf absehbare Frist wieder zur Kolonialmacht aufsteigen würde. Dementsprechend befand es das Amt für unnötig, finanzielle Mittel für kolonialtechnische Spionage aufzuwenden, deren Erfolg zweifelhaft war. ${ }^{71}$ So blieb es auch an dieser Stelle bei reinen Absichtserklärungen, denn eine technische Kommission in der DKG wurde nie gegründet, dennoch lassen sich die Äußerungen durchaus als Hinweis auf einen wahrgenommenen Bedarf verstehen.

Ungeachtet solcher erfahrenen Zustimmung und der umfassenden eigenen Programmatik musste die AKOTECH ihre Ansprüche bereits auf ihrer zweiten Sitzung deutlich reduzieren. Die recht bescheidenen finanziellen Verhältnisse der Arbeitsgemeinschaft sowie ihr provisorischer Charakter zeigten sich beispielhaft daran, dass für Schubert allein schon das Sammeln von Zeitungsartikeln ausländischer Periodika einen großen Gewinn darstellte. ${ }^{72}$ Womöglich nahm er damit gar Bezug auf das Angebot des Auswärtigen Amtes, das zuvor die Bereitstellung fremdsprachiger Fachzeitschriften angeboten hatte. Ebenso schwierig gestaltete sich die Suche nach geeigneten Büroräumen, die

69 DKG an KA AA, 1.10.1924, BArchB, R 8023/377, fol. 225.

70 Ebda.; KA AA an DKG, 6.10.1924, ebda., fol. 224.

71 DKG an KA AA, 1.10.1924, ebda., fol. 225; KA AA an DKG, 6.10.1924, ebda., fol. 224.

72 Vgl. zu den anfänglichen finanziellen Problemen der AKOTECH: AKOTECH an Stresemann, 22.6.1925, BArchB, R 1001/6738, fol. 159-163; AKOTECH an KORAG, 14.11.1924, BArchB, R 8o23/377, fol. 185 f. In dem Schreiben ersuchte Schubert die KORAG, den Mitgliedsbeitrag für die „Studiengesellschaft für Automobilstraßenbau“ von 100 Mark zu übernehmen. Schließlich stimmte das Auswärtige Amt zu, den fälligen Betrag aus dem Propagandafond zu entnehmen: AA an AKOTECH, 28.11.1924, ebda., fol. 184. Vgl. zum Sammeln der Artikel 2. AKOTECH-Sitzung, 23.10.1924, BArchB, R 1001/6738, fol. $39 \mathrm{f}$. 
schließlich vom Reichsausgleichsamt zur Verfügung gestellt wurden, in dem Schubert arbeitete. ${ }^{73}$

Ungeachtet dieser Einschränkungen forderte Schubert in der Deutschen Technischen Warte ambitionierte junge Ingenieure dazu auf, die koloniale Arbeit auch in der Praxis kennenzulernen. Da das Deutsche Reich gegenwärtig nicht über eigene Kolonialgebiete verfüge, müssten Interessierte im Auftrag anderer Kolonialmächte arbeiten, um auf diese Weise die Erfahrungen und Kenntnisse auf dem Gebiet der modernen Kolonialtechnik auf dem aktuellsten Stand zu halten und gleichsam auch die deutsche Position im Ausland zu stärken. ${ }^{74}$ Eine Politik, die starke Überschneidungen mit dem Verhalten von Nationen aufwies, die ebenfalls keine überseeischen Gebiete besaßen, und das Deutsche Reich damit von einer Kolonialnation zu einem „kolonialen Komplizen" degradierte. ${ }^{75}$

Die AKOTECH hoffte bei einem möglichen Ende der deutschen Komplizenschaft und einer erneuten Kolonialtätigkeit durch die erprobten jungen Ingenieure im Zusammenspiel mit dem gesammelten kolonialtechnischen Wissen der "alten Afrikaner“, frühere Fehler zu vermeiden. ${ }^{76}$ Um dieses Ziel zu erreichen, bedurfte es darüber hinaus der gezielten Aus- und Weiterbildung technischer Kräfte, um bei einer sich ergebenden Möglichkeit sofort mit voller Kraft die technische Erschließung und Entwicklung des betreffenden Gebietes voranzutreiben. Derlei Bestrebungen bezeichnete Schubert als „technischen Mobilmachungsplan“, der sofort nach Wiedererlangung der Kolonien anlaufen müsse. ${ }^{77}$ Dementsprechend wäre eine zukünftige koloniale Betätigung unter das Motto zu stellen: "Wiedergewinnen und wiedererschließen!"78 Einen Beitrag zu dieser Zielstellung wollte man vonseiten der AKOTECH mit der

73 Ausgleichsamt an AA, 29.1.1925, BArchB, R 1001/6738, fol. 102.

74 Vogler, Kolonialwissenschaft und Kolonialtechnik, 1924, S. 167 f.; AKOTECH an Stresemann, 3.1.1925, BArchB, R 1001/6738, fol. 71-74.

75 Besonders eindrücklich sind dabei die Ähnlichkeiten zu Betätigungsformen Schweizer Firmen im 19. und beginnenden 20. Jahrhundert, vgl. beispielsweise für die Beteiligung am Handel mit indischer Baumwolle Purtschert u. a., Bestandsaufnahme der postkolonialen Schweiz, 2012. Zur Schweizer Beteiligung am Handel mit indischer Baumwolle: Dejung, Fäden des globalen Marktes, 2013. Vgl. Vuorela, Colonial Complicity, 2009.

76 Anonymus, Arbeitsgemeinschaft der Kolonial- und Auslandstechniker, 1924. In einem Schreiben an Stresemann verwies Schubert ohne Zurückhaltung auf eine ganze Reihe von Unglücken wie den Tunneleinsturz bei der Tanganjika-Bahn oder die Misshandlung der Arbeiter beim Umbau der Strecke Karibib-Windhoek, welche die Erschließung zurückgeworfen und zu ökonomischen Problemen geführt hatten: Schubert an Stresemann, 22.6.1925, BArchB, R 1001/6738, fol. 16o.

77 AKOTECH an KORAG, 9.10.1924, BArchB, R 8023/377, fol. 212 f.; vgl. auch van Laak, Imperiale Infrastruktur, 2004, S. $237 \mathrm{f}$.

78 Schubert, Technik in den deutschen Schutzgebieten, 1926, S. 134. 
Vermittlung von Ingenieuren ins Ausland leisten - so rühmte man sich im ersten Jahresbericht, knapp 40 Ingenieuren und Technikern Beschäftigung im Ausland verschafft zu haben. Der überwiegende Teil war jedoch als Bauund Wegebauingenieure an das griechische Verkehrsministerium vermittelt worden sowie in Gebiete auf dem Balkan und nach Mittelamerika. Lediglich drei Ingenieure hatten dank der Arbeitsgemeinschaft eine Beschäftigung auf dem afrikanischen Kontinent erhalten. Somit erfüllte sie ihre eigentlichen Ansprüche nicht, einen Grundstock junger, in der Praxis geschulter Kolonialingenieure in ihren Reihen zu versammeln. ${ }^{79}$

Diese Politik der Stellenvermittlung verfolgte drei unterschiedliche Ziele: ${ }^{80}$ Zum einen versuchte die AKOTECH, den Ingenieuren ebenjene Auslandserfahrung zu ermöglichen, wie man sie für die Arbeit in den eigenen Kolonien bedurfte, zweitens spielten auch außenwirtschaftliche Ziele wie die Steigerung des Exports eine bedeutende Rolle, drittens kann dieses Vorgehen unter dem Gesichtspunkt der informellen, wirtschaftlichen Durchdringung afrikanischer Gebiete betrachtet werden. Dieses Vorgehen war bereits vom früheren Gouverneur und späteren Leiter der Kolonialabteilung, von Brückner, in seinen Richtlinien für die Kolonialpolitik propagiert worden. ${ }^{81}$ Solch einer konzeptionellen Ausrichtung fühlte sich auch die AKOTECH verbunden, wenn sie mit Blick auf die Auslandsarbeit der Ingenieure die „Wiedergewinnung der deutschen Weltgeltung durch Mittel des Friedens“ prophezeite. ${ }^{82}$ Die 1895 gegründete Société française des ingénieurs coloniaux wirkte auch in den 1920er-Jahren noch in einem weltumspannenden Kolonialreich, doch teilte sie mit ihrem deutschen Pendant andere Zielstellungen. Neben dem gleichnamigen Bulletin de la Société, das bis 1949 erschien, sollte auch die französische

79 Vgl. AKOTECH an Stresemann (Anlage), 11.8.1925, BArchB, R 10o1/6738, fol. 187. Laut diesem Schreiben wurden sogar 65 Ingenieure und Techniker ins Ausland vermittelt. Dass Arbeitssuchende in Afrika ausschließlich nach Angola vermittelt werden konnten, kann zum Teil durch die Vita Schuberts erklärt werden. Dieser war vor seiner Tätigkeit in der AKOTECH unter anderem auch an einer 1914 durchgeführten Expedition in die portugiesische Kolonie Angola beteiligt: vgl. BArchB, R 1001/6738, fol. 56; Schubert, Technik in den deutschen Schutzgebieten, 1926, S. 511 (Anhang); Rinke, Freie Kontinent, 1996, S. 246 f.

8o Ähnliche Bestrebungen lassen sich bereits für die 188oer-Jahre nachweisen, wobei jedoch die Ventilfunktion solcher Maßnahmen besonders betont wurde: Jannasch/ Roscher, Kolonien, Kolonialpolitik und Auswanderung, 1885; vgl. allg. Hemme, Hände im Uebermaß, 2005, S. $5^{2}$.

81 Vgl. Politisches Archiv des Auswärtigen Amts (PA AA), Büro Staatssekretär X (betr. Kolonialfragen) StS X, Bd. 1, fol. E 187034-36 zit. nach: Hinnenberg, Die deutschen Bestrebungen, 1973, S. 18-20.

82 Richter, Vorwort, 1929. 
Gesellschaft den speziellen Herausforderungen der kolonialen Ingenieursarbeit Rechnung tragen und ein Forum für den gemeinsamen Erfahrungsaustausch bieten. ${ }^{83}$

In den 1920er- und 3oer-Jahren war die AKOTECH neben der propagandistischen Glorifizierung der kolonialen Arbeit und des in Afrika von den Ingenieuren Erreichten besonders im Bereich des technischen Ausstellungswesens aktiv. Darüber hinaus gab es Bestrebungen, die eigenen Inhalte und Zielsetzungen in ein reguläres Hochschulstudium zu überführen. Die letzten beiden Aspekte werden gesondert im Rahmen eines eigenen Kapitels untersucht. Ganz unzweifelhaft blieb jedoch, dass der Arbeitsgemeinschaft daran gelegen war, die Ingenieursgruppe als wichtigen kolonialen Akteur zu etablieren: „Es darf wohl gesagt werden, dass für eine neu in Aktion tretende Kolonialverwaltung der Techniker neben dem Arzt der unentbehrlichste Gehilfe sein wird. “84

\subsection{Kolonialtechnik im Nationalsozialismus}

Vor dem Hintergrund immer wieder aufflammender Diskussionen über einen Zusammenhang oder gar eine Pfadabhängigkeit zwischen kolonialen und nationalsozialistischen Verbrechen wird im Folgenden der Frage nachgegangen, welche Stellung die deutsche Kolonialtechnik in den 3oer- und 4oer-Jahren des 20. Jahrhunderts einnahm und welche Aufgabe ihr im Zweiten Weltkrieg hinsichtlich einer Erschließung osteuropäischer Gebiete zugedacht wurde. ${ }^{85}$ Neben dem allgemeinen Wiederaufleben kolonialer Großmachtfantasien im Sinne eines deutschen Mittelafrikas ${ }^{86}$ und ihrem abrupten Ableben in der ersten Hälfte der 1940er-Jahre wird der Fokus vor allem auf solche Vorhaben gerichtet, die in den Bereich der Kolonialtechnik fallen sowie einen weiterführenden Blick auf den beruflichen Werdegang einzelner Kolonialingenieure werfen.

83 Gobe, Jalons, 2015, S. 21 f.; Vacher, Métier à la Profession, 2001, S. 174.

84 AKOTECH an Stresemann, 22.6.1925, BArchB, R 10o1/6738, fol. 16 o.

85 Für den Diskurs über die Stellung der technischen Profession im Nationalsozialismus vor allem hinsichtlich einer möglichen Modernisierungswirkung derselben in den 193oer- und 4oer-Jahren, vgl. einleitend: Lorenz/Meyer, Einführung, 2004; sowie Herf, Reactionary Modernism, 1993; Matzerath u. a., Modernisierungstheorie, 1977.

86 Vgl. zum Aufkommen dieses Topos bereits im Ersten Weltkrieg: Leutwein, Mitteleuropa - Mittelafrika, 1917; für die spätere Entwicklung des Begriffes: Wedi-Pascha, Deutsche Mittelafrika-Politik, 1992; Tschapek, Bausteine, 2000. 
Die Idee eines deutschen Mittelafrikas als zusammenhängendes Kolonialgebiet im Zentrum des Kontinents findet sich bereits in den ersten Jahren deutscher Kolonialaktivität. ${ }^{87}$ Dieses Projekt sollte vor allem durch wirtschaftliche und diplomatische Einigung mit den übrigen europäischen Kolonialmächten realisiert werden. Es ist dabei eher als allgemeine Vorstellung zu verstehen, denn als ausgearbeitetes Konzept, wie es Leutwein in seiner Denkschrift formulierte. Unter dem Eindruck des Ersten Weltkrieges erläuterte er darin die Vorteile eines geschlossenen mittelafrikanischen Kolonialgebiets hinsichtlich der Möglichkeit, es zu verteidigen. Als imperiale Verhandlungsmasse sollten bei Bedarf auch die bestehenden deutschen Schutzgebiete dienen. ${ }^{88}$

Sowohl in den Jahren vor dem Ersten Weltkrieg als auch während der Zeit der Weimarer Republik fand das Konzept nur begrenzt Aufmerksamkeit. Erst unter den Nationalsozialisten erlebte das Konzept Mittelafrika eine Renaissance. ${ }^{89}$ Mit Blick auf diese Bestrebungen vertrat der Historiker Klaus Hildebrand die These, für Adolf Hitler hätten die Kolonien lediglich als Verhandlungsmasse auch bezüglich eines möglichen Friedensvertrages mit Großbritannien einen Wert besessen. ${ }^{90}$ Für den Machtapparat der Nationalsozialisten waren koloniale Erwerbungen und Ziele ebenfalls nur so lange von Interesse, wie sie die Bestrebungen nach dem Lebensraum im Osten nicht beeinträchtigten und dieses prioritär blieb. Es ist also durchaus nachvollziehbar, von einer gewissen Konkurrenz der beiden Bereiche zu sprechen. ${ }^{91}$

Der immer wieder vorgebrachte Hinweis auf eine mögliche Gleichsetzung der eroberten sowjetischen Gebiete mit einem deutschen Indien ist vor allem im Hinblick auf die Bedeutung zu verstehen, die der Subkontinent für die Kolonialmacht einnahm und welche wirtschaftlichen Hoffnungen sich von deutscher Seite mit Osteuropa verbanden. ${ }^{92}$ "Was für England Indien war, wird für uns der Ostraum sein. ${ }^{93}$ Die koloniale Bewegung konnte dementsprechend nur auf finanzielle und ideologische Unterstützung hoffen, wenn die Eroberung afrikanischer Gebiete mit strategischen oder politischen

87 Vgl. u. a. Tschapek, Bausteine, 200o, S. 281 f.; Wedi-Pascha, Deutsche Mittelafrika-Politik, 1992, S. 61 f., 227 f.

88 Leutwein, Mitteleuropa - Mittelafrika, 1917, v. a. S. 46-5o.

89 Vgl. Linne, Deutschland jenseits, 2008, S. 75-77.

90 Vgl. Hildebrand, Reich zum Weltreich, 1969, S. 26o-262.

91 Vgl. Pogge von Strandmann, Imperialism and Revisionism, 1986, S. 10o; van Laak, Berliner Arbeitsgemeinschaft, 2005, S. 122.

92 Zimmerer, Nationalismus postkolonial, 2009, S. $542 \mathrm{f}$.

93 Picker, Hitlers Tischgespräche, 1993, S. 69, vgl. auch S. 317; ebenso Hildebrand, Reich zum Weltreich, 1969, S. 715 f. In einem ganz ähnlichen Verständnis dieser Begrifflichkeit wurde auch Carl Peters das Ziel zugeschrieben, ein „deutsches Indien in Afrika“ zu errichten: Wedi-Pascha, Deutsche Mittelafrika-Politik, 1992, S. 75 . 
Vorteilen einherging und ausreichend militärische Ressourcen vorhanden waren, um die primären Kriegsziele zu verfolgen.

Anstatt einer wirklichen Begeisterung der nationalsozialistischen Eliten für die kolonialen Diskurse mag man hier das Sinnbild eines Strohfeuers anführen. Die Hoffnung der Revisionisten richtete sich vor allem auf mögliche Annexionsforderungen der Deutschen in Afrika nach einem siegreichen Kriegsausgang. ${ }^{94}$ Für Hitler lag der Fokus dagegen klar auf dem europäischen Osten, da nur dieser, im Gegensatz zu den Kolonien, dauerhaft militärisch zu sichern sei. Dies bedeutete aber eben nicht, dass er sich kolonialen Forderungen rundweg verweigerte, wenn sie für ihn auch nur eine nachrangige Priorität besaßen. ${ }^{95}$ Ungeachtet dieser Rangfolge führten allein schon argumentative Verweise auf eine mögliche Wiedererlangung der deutschen Kolonialgebiete, wie später dann auch die Hoffnungen, die jene Kreise auf die mögliche Okkupation der französischen Besitzungen in Afrika setzten, zu einer Art Selbstmobilisierung, wie sie bereits für den Bereich der Naturwissenschaft und Technik herausgearbeitet worden ist. ${ }^{96}$

Die zweite Hälfte der 193oer-Jahre bildete dabei ohne Zweifel einen Höhepunkt kolonialtechnischer Begeisterung. Im Besonderen manifestierte sich diese Entwicklung in den zahlreichen entsprechenden Beiträgen und Sonderausgaben technischer Fachzeitschriften. ${ }^{97}$ Allein der Reichsbahndirektionspräsident und Hauptabteilungsleiter im Kolonialpolitischen Amt (KPA) der Nationalsozialistischen Deutschen Arbeiterpartei (NSDAP) für die Abteilung IV „Verkehr und Technik“, Dr.-Ing. Karl Remy, veröffentlichte zwischen 1937 und 1941 mehr als 30 Artikel in technischen und kolonialen Fachzeitschriften, die die afrikanische Verkehrspolitik sowie den Ausbau kolonialer Infrastruktur zum Thema hatten. ${ }^{98}$

\subsubsection{Arbeitsgemeinschaft der Auslandsingenieure}

Seit dem Winter 1929 gab es mit der Arbeitsgemeinschaft der Auslandsingenieure (ADA) einen weiteren Zusammenschluss, der sich dezidiert an technische Experten wandte, die nicht ausschließlich in Deutschland beschäftigt waren. Wie aus den Artikeln der Vereinszeitschrift, dem

\footnotetext{
94 Vgl. Pogge von Strandmann, Imperialism and Revisionism, 1986, S. 101 f.

95 Vgl. Hildebrand, Reich zum Weltreich, 1969, S. 715 f.; Kundrus, Reichskolonialamt, 2005, S. 16.

96 Vgl. Ludwig, Technik und Ingenieure, 2010, S. 15-20.

97 van Laak, Berliner Arbeitsgemeinschaft, 2005, S. 121 f.; u. a. Technik und Kolonien (Sonderheft), 1938, S. 17, 6o.

98 Remy, Verkehrsarbeit (Vortrag), ca. 1941/42, S. 29 f., BArchB, NS 52/99; vgl. auch Hildebrand, Reich zum Weltreich, 1969, S. 734.
} 
Nachrichtenblatt der Arbeitsgemeinschaft der Auslandsingenieure, die seit dem Sommer 1932 regelmäßig erschien, hervorgeht, fanden sich hier neben Ingenieuren, die im deutschen Exportgeschäft tätig waren, auch jene wieder, die vor dem Ersten Weltkrieg im deutschen Pachtgebiet in Kiautschou gewirkt hatten. Trotz der grundsätzlich unterschiedlichen Ausrichtung der ADA, einer Untergruppierung des VDI, und der AKOTECH gab es thematisch doch immer wieder Übereinstimmungen, da auch die Kolonialtechniker aufgrund der realpolitischen Lage von einem reinen Fokus auf die ehemaligen Schutzgebiete abwichen. Dementsprechend beschäftigte sich auch die AKOTECH immer wieder mit außenhandelspolitischen Fragestellungen.

Eine enge Zusammenarbeit der beiden Organisationen war Marinebaurat a. D. Erich Röhlke zufolge bereits bei einer gemeinsamen Tagung Ende August 1930 beschlossen worden. Neben den thematischen Überschneidungen der beiden Ingenieursvereine unterschieden sie sich doch in ihrer grundsätzlichen Ausrichtung. Der starke kolonial-revisionistische Fokus der AKOTECH ließ sich bei der ADA so nicht finden. Dies mag begründen, warum trotz der vereinbarten Zusammenarbeit die ersten wirklichen Annäherungsversuche der beiden Vereine erst für den Februar des Jahres 1933 zu belegen sind. Auf einer von der ADA ausgerichteten Versammlung, bei der neben dem VDIVorsitzenden Waldemar Hellmich auch Röhlke anwesend war, vereinbarten die beiden Organisationen nach einem Abgleich der jeweiligen Arbeitsprogramme die Ausweitung ihrer Zusammenarbeit. Diese sollte sich jedoch vorerst 1933 und 1934 in der gemeinsamen Durchführung sogenannter Sprechnachmittage („Kolloquien“) erschöpfen. ${ }^{99}$

Offiziell waren es finanzielle Probleme sowie Überschneidungen der Agenda beider Arbeitsgemeinschaften, die zum Zusammenschluss der ADA mit der AKOTECH am 1. März 1936 führten. Darauf, dass der finanzielle Aspekt eine nicht zu verachtende Rolle bei dieser Entscheidung gespielt haben mag, deuteten bereits die Äußerungen in den frühen Ausgaben des Nachrichtenblatts der ADA sowie die einfache und qualitativ minderwertige Ausführung der Zeitschrift hin. ${ }^{100}$ Vonseiten des VDI hatte man bereits 1931 und damit nicht einmal zwei Jahre nach ihrer Gründung die Auflösung der

99 Vgl. Nachrichtenblatt der ADA, Januar 1933 (Nr. 8), S. 6; ebda., Februar 1933 (Nr. 9), S. 2 f.; ebda., März/April 1934 (Nr. 20).

100 Vgl. Nachrichtenblatt der ADA, April 1933 (Nr. 11), S. 4. Beim Nachrichtenblatt handelte es sich lediglich um eine wenige Seiten umfassende Schrift, die in ihrer Erscheinung keinesfalls mit den Veröffentlichungen des VDI oder auch des RDT und der AKOTECH zu vergleichen war. Das Magazin führte auch keine separaten Artikel auf. Sämtliche Äußerungen gingen allein auf den Vorsitzenden Maximilian Esterer sowie den Schriftleiter C. Krause zurück. 
ADA erwogen, ihre Zielstellung aber für notwendig erachtet und ihre Arbeit daher notdürftig aufrechterhalten. ${ }^{101}$ Nach der Vereinigung der beiden Ingenieursgruppierungen wurde die gemeinsame Zeitschrift unter dem Namen Die Auslandstechnik. Mitteilungsblatt der AKOTECH herausgegeben, die seit Mai 1937 unter der Bezeichnung Der Deutsche Auslandsingenieur firmierte. Mit dem sogenannten Nachrichtenblatt der AKOTECH hatte die Arbeitsgemeinschaft bereits in den Jahren zuvor Propaganda für die kolonialtechnische Sache betrieben. Thematisch bediente die Schriftleitung nach der Fusion beide Bereiche. Berichte über kolonialtechnische Fragen, vor allem mit Verweis auf die historischen Leistungen der Deutschen in Afrika, standen neben der argumentativen Betonung der Bedeutung der Ausfuhrwirtschaft sowie der Stellung deutscher Unternehmen im Ausland, wobei die aktuellen ökonomischen Fragen einen Schwerpunkt bildeten. ${ }^{102}$

Der Zusammenschluss beider Organisationen firmierte unter dem Namen ,AKOTECH im VDI' und hatte es sich zur Aufgabe gemacht, „die Ausbreitung der deutschen Technik durch Betreuung und Hilfsstellung an den deutschen Technikern aller Grade und Fachrichtungen, vorzüglich im Ausland, zu fördern“. ${ }^{103}$ Bereits 1936 lag der Schwerpunkt der in der Auslandstechnik veröffentlichten Artikel auf dezidiert kolonialtechnischen Themen wie dem ,Tropenhaus' oder klassisch kolonialrevisionistischen Problematiken wie der propagierten Notwendigkeit der Rückgewinnung deutscher Kolonialgebiete für die heimische Wirtschaft. ${ }^{104}$ Maximilian Esterer (188o-1956), der in der Folge den Vorsitz über die vereinigten Arbeitsgemeinschaften führte, verfügte selbst über einen illustren Erfahrungsschatz auch als Kolonialingenieur. ${ }^{105}$ Bereits vor dem Ersten Weltkrieg war er für eine deutsche Maschinenfirma im Kiautschou-Gebiet tätig gewesen und in dieser Funktion auch an der Errichtung von Wasserkraftanlagen in China beteiligt. Dieser Anstellung folgten Studienreisen nach Südamerika und Russland, bis er seine Tätigkeit bei der Überseeabteilung von Siemens \& Halske aufnahm. ${ }^{106}$

Parallel zur institutionellen Entwicklung der beiden Organisationen bis zu ihrem Zusammenschluss lässt sich der Schwerpunkt ihrer Aktivitäten insbesondere auf drei Gebiete beschränken: zum einen die allgemeine

\footnotetext{
101 Nachrichtenblatt der ADA, Februar 1933 (Nr. 9), S. 2 f.

102 Vgl. dazu das Leitwort der ersten Ausgabe: Esterer, Verbundenheit, 1936, S. 1.

103 Anonymus, Ohne Titel, 1936.

104 Vgl. Thiel, Tropenhaus, 1936, S. 9 f.; für die Kolonialbewegung insgesamt Hildebrand, Reich zum Weltreich, 1969, S. 109-112.

105 Röhlke, AKOTECH, 1936, S. 2 f.

106 Nachrichtenblatt der ADA, Februar 1933 (Nr. 9), S. 5 f.; Martin, Deutsch-chinesische Beziehungen, 2003, S. 333, 527.
} 
Kolonialpropaganda unter Betonung technischer Aspekte in Vorträgen und Artikeln, die wie ausgeführt klar kolonialrevisionistisch ausgerichtet waren, zum anderen das kolonialtechnische Ausstellungswesen wie auch der Versuch einer institutionalisierten Aus- und Weiterbildung für Ingenieure in diesem Bereich.

\subsubsection{Kolonialtechnisches Ausstellungswesen}

Die Bekanntheit und Bedeutung der Kolonialtechnik, die während der Weimarer Republik - vor allem aber in den 1930er-Jahren - einen deutlichen Aufschwung erfuhr, lässt sich nicht nur anhand der aufgezeigten organisationalen Entwicklungen erkennen, sondern auch am kolonialtechnischen Ausstellungswesen.

Eine der frühen deutschen Ausstellungen, bei der dem interessierten Publikum Verfahren und Maschinen, die auf die tropischen Verhältnisse und Rohstoffe angepasst waren, präsentiert werden sollten, war die für 1914 in Dar es Salaam geplante Landesausstellung. Um die Entwicklung der ostafrikanischen Kolonie einer breiteren Öffentlichkeit vorzustellen, plante das KWK in Zusammenarbeit mit dem RKA und der eigens 1906 zur Koordination von Veranstaltungen im Ausland gegründeten Ständigen Ausstellungskommission der Deutschen Industrie diese zweite ostafrikanische Landesausstellung am Gouvernementssitz. Ein Jahrzehnt nach der ersten Veranstaltung hatte man sich damit gegen den ursprünglichen Termin und auch gegen Moshi als Veranstaltungsort entschieden. Der Grund hierfür ist nicht nur im fünfundzwanzigjährigen Jubiläum der hiesigen Schutztruppe ein Jahr später, 1914, zu finden, sondern kann insbesondere auf die Fertigstellung der Tanganjika-Bahn zurückgeführt werden. Deren vollständige Freigabe für den öffentlichen Verkehr auf den mehr als 1.20o Kilometern, ausgehend von Dar es Salaam bis an die Küste des Tanganjika-Sees, wollte man festlich mit der Eröffnung der zweiten Landesausstellung begehen. Mit dieser Überlandbahn befände sich die Kolonie, nach Ansicht der deutschen Kolonialmacht, „an der Schwelle einer neuen Epoche seiner wirtschaftlichen Entwicklung “. ${ }^{107}$ Als Ziel der Veranstaltung propagierten die Initiatoren die Steigerung des kolonialen Exports nach Deutschland sowie reziprok das Eröffnen kolonialer Märkte. ${ }^{108}$

107 Denkschrift, Landesausstellung in Daressalam, Juli 1913, BArchB, R 10o1/161, fol. 191; Ständige Ausstellungskommission an RKA, 2.9.1912, ebda.; Anonymus, Offizieller Katalog, 1914, S. 17-22.

108 Vgl. Gouvernement (DOA) an Ständige Ausstellungskommission, 6.2.1913, BArchB, R 1001/161, fol. 21; Vorläufiger Arbeitsplan, 1914, BArchB, R 8024/52. 
Den erwarteten europäischen Besuchern und Ausstellern plante man ebenfalls, einen ethnologischen Bereich zu präsentieren, in Anlehnung an Völkerschauen in Europa, die rassistische Stereotype zuerst konstruierten, um sie in der Folge immer wieder aufzugreifen und zu zementieren. ${ }^{109}$ Für die Landesausstellung führte dies zur skurrilen Entwicklung, dass bereits 1913 geplant wurde, einzelne Familien und Stämme auf dem späteren Ausstellungsgelände anzusiedeln, um dem Besucher die ,eigenwilligen' Hausbauten, Trachten und Waffen zu präsentieren - ein Ausstellungsbereich, der den Charme und die Attraktivität des Wilden in den europäisch geprägten kolonialen Brückenkopf an der Küste des Indischen Ozeans (zurück)bringen sollte, verbunden mit einer Zurschaustellung kolonialer Bräuche und Sitten der betreffenden Kolonie. ${ }^{110}$ Mutet dieses Vorgehen in der Rückschau recht seltsam an, so ist es dennoch ein Beleg für das gedankliche Konstrukt, zu dem sich die afrikanischen Kolonien in der deutschen Wahrnehmung entwickelt hatten. Den Planern der Ausstellung können wohl Bedenken unterstellt werden, dass Dar es Salaam und dessen Umgebung repräsentativ nicht kolonial beziehungsweise wild genug erschienen und daher solch einer ethnologischen Auffrischung bedurften. Der Ausbruch des Ersten Weltkrieges führte letztlich zur Absage der Ausstellung.

Nach diesem ersten Versuch, speziell auf den tropischen beziehungsweise kolonialen Kontext angepasste Technik in einem größeren Rahmen zu präsentieren, sollte es erst Mitte der 1920er-Jahre wieder ein ähnliches Projekt geben. Die Initiative, einen kolonialtechnischen Fachbereich auf der Leipziger Messe zu etablieren, geht wohl auf das Messeamt für die Mustermesse in Leipzig zurück. Deren Mitarbeiter hatten von der Gründung der AKOTECH erfahren, in der "Kreise, die früher oder jetzt in den Kolonien als Techniker tätig sind, zusammengeschlossen werden“, und versuchten, diese Gruppe für eine Zusammenarbeit zu gewinnen. ${ }^{111} \mathrm{Zu}$ einer ersten Besprechung zwischen den Vorsitzenden der AKOTECH, Schubert und Röhlke, sowie Dr. Köhler und Dr. Reisner von der Leipziger Messe kam es bereits im September 1925. ${ }^{112}$ Zwar fanden sich schon zu diesem Zeitpunkt einige landwirtschaftliche Maschinen auf der halbjährig stattfindenden Messe, die dem Bereich der Kolonialtechnik zuzurechnen sind. Dabei handelte es sich jedoch noch nicht um

\footnotetext{
109 Vgl. dazu u. a. Lingelbach, War da was, 2008; Honold, Ausstellung des Fremden, 2004, S. 170-19o; Großbölting, Reich der Arbeit, 2008, S. 402; vgl. zu dieser Thematik für die Zeit nach 1933: Lewerenz, Deutsche Afrika-Schau, 2006, S. 69-72.

110 Vgl. Zeitungsausschnitt, 1913, BArchB, R 1001/161, fol. 36.

111 Brauer an Westphal, 8.2.1925, Sächsisches Staatsarchiv, Staatsarchiv Leipzig (SächStA-L), 20202, Nr. 225, fol. 182; Reisner an Brauer, 11.9.1925, ebda., fol. 191.

112 Köhler, Aktennotiz, 2.9.1925, ebda., fol. 212; Köhler an AKOTECH, 30.3.1926, ebda., fol. 219.
} 
eine eigenständige Fachgruppe, wie sie in späteren Jahren realisiert werden konnte. ${ }^{113}$

Einige Wochen nach dem Treffen wandte sich die AKOTECH mit dem Anliegen, solch eine "Sondergruppe für Auslands- und Kolonialbedarf“ zu etablieren, sowohl an die eigenen Mitglieder als auch an die übergeordnete KORAG. In dem Rundschreiben forderten die Vorsitzenden, dass tropengeeignete Maschinen nicht nur möglichst einfach zu bedienen, sondern auch hinsichtlich ihrer Verschleißelemente weitgehend normiert sein müssten, um Probleme bei der Versorgung mit Ersatzteilen zu minimieren. ${ }^{114}$ Bereits im Folgejahr 1926 gelang es den „Berliner Kolonialherren“, zumindest eine kleine ,Sondergruppe ${ }^{6}$ auf der Leipziger Messe einzurichten. ${ }^{115}$ Das Unterfangen war wohl von Erfolg gekrönt, wie die mehr als 500 mündlichen Anfragen zu kolonialen Maschinen, aber auch zur Arbeit in den Schutzgebieten selbst bezeugen. Dementsprechend wünschte auch das verantwortliche Messeamt in Person Dr. Köhlers, mit Geheimrat Schubert über die „weitere Ausgestaltung der Auslands- und Kolonialbedarfsmesse zu sprechen. ${ }^{\text {116 }}$ Im Rahmen der Technischen Messe in Leipzig richtete man schließlich 1928 eine eigene Abteilung für Tropen- und Kolonialbedarf ein, wie sie zuvor zwischen der DKG und der AKOTECH vereinbart worden war. ${ }^{117}$

Der Durchbruch für das kolonialtechnische Ausstellungswesen vollzog sich jedoch erst in den 193oer-Jahren mit der zuvor behandelten Annäherung der beiden großen "Vertreter des Auslandsingenieurstum[s]“, der ADA und der AKOTECH. Der Vorsitzende der ADA, Maximilian Esterer, äußerte sich durchaus zustimmend zu einem erneuten Ausstellungsvorhaben. Er verwies darauf, dass einige Jahre zuvor ein ganz ähnlicher Versuch gescheitert sei. ${ }^{118}$ Trotz dieser Bedenken unterstützte die AKOTECH in Person ihres Mitglieds Erich Köthe das Messeamt seit 1934 bei der Planung und Vorbereitung einer kolonialtechnischen "Sonderschau für Tropenbedarf und Auslandssiedlung“ für das Frühjahr 1935 in Zusammenarbeit mit dem „Forschungszentrum für

113 Meßamt für Mustermessen, Technische Messe, 1925, S. 23, 31.

114 Rundschreiben AKOTECH, 3.11.1925, BArchB, R 8023/377, fol. 141-143; AKOTECH an KORAG, 23.11.1925, ebda., fol. 123-130.

115 Köhler an Reisner, SächStA-L, 20202, Nr. 225, fol. 213.

116 Köhler an AKOTECH, 30.3.1926, SächStA-L, 202O2, Nr. 225, fol. 219; AKOTECH an Köhler, 20.3.1926, ebda., fol. 218. Das Polytechnische Journal äußerte sich ebenfalls sehr wohlwollend über die „neue Fachausstellung“: Anonymus, Polytechnische Schau, 1926.

117 Anonymus, Wie urteilt die Welt, 1928, S. 3; AKOTECH an DKG, BArchB, R 1001/6738, fol. 27 .

118 Esterer an Leipziger Messeamt, 24.1.1934, SächStA-L, 20202, Nr. 226, fol. 313. 
Tropen- und Siedlungstechnik“ in Berlin. ${ }^{119}$ Anlässlich dieser Ausstellung lud die AKOTECH mit Unterstützung der ADA zur ersten „Tagung der deutschen Auslandsingenieure" ein und bot den ehemaligen Kolonial- sowie den aktiven Auslandsingenieuren ein gemeinsames Forum. ${ }^{120}$

Die Herausbildung einer eigenständigen Kolonial- und Tropentechnischen Messe im Frühjahr 1937 wertet Dirk van Laak als Hinweis, dass es vor allem Ingenieure und Techniker waren, die auf die „Vorbereitung für das kommende Kolonialreich drängten" ${ }^{121}$ Dabei darf jedoch keinesfalls die in diesem Kontext immer wieder betonte Ausrichtung auf die Exportwirtschaft übersehen werden. Dies verdeutlichte auch Karl Krüger, der Schriftleiter der Auslandstechnik, der Zeitschrift der vereinigten ADA und AKOTECH, wenn er sich zur Metapher hinreißen lässt: „Mitten im brasilianischen Urwald dampfen deutsche Lokomotiven und singen in ihrer Melodie das Hohe Lied deutschen Fleißes und deutschen Geistes“, um den „Auslandsingenieur" eher als „Kämpfer für die Wirtschaftswerbung auf vorgeschobenen Posten“ zu definieren denn als klassischen Kolonisator. ${ }^{122}$ Für den Erfolg dieses erneuten Versuches, die Kolonialtechnik im Fahrwasser einer exportorientierten Auslandstechnik einer interessierten Öffentlichkeit auf dem Feld vor dem Leipziger Völkerschlachtdenkmal im Rahmen einer Ausstellung zu präsentieren, sprechen die Wiederholungen 1938 und 1939. Neben der Akquise neuer Kunden stand auch hier der Beweis deutscher Kolonisationsfähigkeit im Vordergrund, die ihren sichtbaren Ausdruck in der Implementierung von Maschinen und dem Bau technischer Infrastruktur fand. ${ }^{23}$

Die Kolonial- und Tropentechnischen Messen präsentierten, was technisch möglich war, und sollten dementsprechend zu einer Akkumulation von symbolischem Kapital beitragen. Bis zum Kriegsausbruch wurden sie in regelmäßigen Abständen organisiert, während des Zweiten Weltkrieges jedoch auf die Arbeit der Kolonialtechnischen Beratungsstelle reduziert, wie dem Kolonialen Taschenbuch von 1942 zu entnehmen ist. ${ }^{124}$

\footnotetext{
119 AKOTECH an Leipziger Messeamt, 3.9.1934, ebda., Nr. 227, fol. 147; Anonymus, Sonderschau für Tropenbedarf, 1935.

120 Röhlke, Vorwort, 1935.

121 Vgl. van Laak, Berliner Arbeitsgemeinschaft, 2005, S. $121 \mathrm{f}$.

122 Krüger, Kolonial- und Tropentechnische Messe, 1937, S. 21.

123 Vgl. Köthe, Messebericht, 15.3.1937, SächStA-L, 20202, Nr. 228, fol. 92 f.; Lingelbach, War da was, 2008, S. 59; Anonymus, Werbeanzeige für die Bergakademie Freiberg, 1938.

124 Bundesführung des Reichskolonialbundes, Koloniales Taschenbuch 1942, 1941, S. 187.
} 


\subsubsection{Zertifizierte Kolonialingenieure}

Neben dem bereits angeführten wenig erfolgreichen Versuch der AKOTECH, einzelnen Ingenieuren im kolonialen Afrika eine Anstellung zu vermitteln und diesen somit die Gelegenheit zum Sammeln praktischer Erfahrung zu eröffnen, verfolgte die Arbeitsgemeinschaft auch den Ansatz einer spezialisierten theoretischen Ausbildung für Kolonialtechniker in Deutschland. Ohne sich explizit darauf zu berufen, knüpfte sie damit an die Arbeit des FriedrichsPolytechnikums in Köthen zu Beginn des 2o. Jahrhunderts an.

Auf Betreiben des hiesigen „zionistisch-akademischen Vereins“, kurz Tchioh, und mit tatkräftiger Unterstützung des Köthener Direktors Karl Friedrich Foehr (186o-1930) fand zwischen 1905 und 1908 jeweils im April und November ein Ferienkursus für koloniale Technik statt. ${ }^{125}$ Mit Johann Albrecht von Mecklenburg, der 1895 zum Vorsitzenden der DKG gewählt worden war, hatte Foehr einen finanzstarken und willigen Gönner für sich gewinnen können. Die bis zu 200 Zuhörer pro Kursus rekrutierten sich jedoch nicht nur aus der hiesigen Technikerschaft, sondern ebenso aus interessierten Geografen, Medizinern und Volkswirten. ${ }^{126}$ Zwar gab es auch im frühen 20. Jahrhundert mit dem Seminar für Orientalische Sprachen, dem Hamburger Kolonialinstitut wie auch mit der Kolonialschule Witzenhausen bereits Einrichtungen, deren Anliegen eine Vor- beziehungsweise Ausbildung für eine Betätigung in den Kolonien darstellte, doch richtete sich keine dieser Institutionen explizit an Techniker oder Ingenieure. Ziel des Köthener Kursus war zwar nicht die Herausbildung eines eigenständigen Berufszweigs der Kolonialtechniker, dennoch hatte man die sorgfältige Vorbereitung der Zuhörer im Blick, auch um eine spätere Wiedereingliederung in den heimischen Beamtenapparat $\mathrm{zu}$ vereinfachen. ${ }^{127}$ Trotz der Wiederholung des Kursus blieb er in seiner

125 Curatoriums Sitzung, 10.1.1905, Hochschularchiv Anhalt, Köthen, Curatorium 1. Bestand 13; Schulz an Foehr, 17.1.1905, ebda.; Städtisches Friedrichs-Polytechnikum, Ferienkursus für koloniale Technik, 1905; ebda., Ferienkursus für koloniale Technik, 19o6; ebda., Ferienkursus für koloniale Technik, 19o8. Vgl. zu den nicht weiter ausgeführten inhaltlichen Übereinstimmungen zwischen deutscher Kolonialtechnik und zionistischen Bestrebungen im frühen 20. Jahrhundert: Saudler, Coethener Kurse 1905; Warburg, Palästina, 1904; Vogt, Subalterne Positionierungen, 2016, S. 185 f. Im Jahr 1908 war die "zionistische Arbeit für Palästina“ jedoch zunehmend in den Hintergrund gerückt: Foehr, Kolonialwoche, 1908, S. 2.

126 Ebda., S. 8 f.

127 Foehr hielt die Zeit jedoch noch nicht für gekommen, um „eine besondere Abteilung für Kolonialingenieure an unserem Institut" einzurichten: Foehr an Magistrat, 24.12.1904, HArch-Kö, 1. Bestand 27, fol. 1; Foehr, Kolonialingenieur, 1910, S. 165; vgl. Ruppenthal, Kolonialismus, 2007, u. a. S. 37-39; Linne, Witzenhausen, 2008, S. 125-130; Gouaffo, Wissens- und Kulturtransfer, 2007, S. 42-44. 
Außenwirkung recht beschränkt. Selbst in der Wahrnehmung der Kolonialingenieure war er nicht präsent genug, dass sich die AKOTECH als ihre Interessenvertretung in der Zwischenkriegszeit hierauf bezogen hätte.

Auf den Direktor des Polytechnikums, Foehr, geht jedoch mit großer Wahrscheinlichkeit die erste Nennung des Titels Kolonialingenieur in seinem gleichnamigen Aufsatz in den Cöthener Akademischen Blättern im Mai 1910 zurück. Hierin schlägt er vor, dass zukünftige Kolonialingenieure nach dem erfolgreichen Erwerb ihres technischen Diploms für zwei Semester an das Hamburger Kolonialinstitut wechseln sollten, um hier ein zusätzliches Kolonialdiplom zu erwerben. ${ }^{128}$ Dieser erste Ansatz blieb in seiner Reichweite recht beschränkt und wurde bereits 1910 endgültig verworfen.

Erst Mitte der 1920er-Jahre wurde von der AKOTECH wieder die Notwendigkeit eines eigenständigen kolonialtechnischen Studienganges für die Ausbildung der in den kommenden Jahren in die Kolonien zu entsendenden Techniker und Ingenieure propagiert. In der Realität musste man sich jedoch neben derVeröffentlichung von Artikeln in technischen Fach-und Kolonialzeitschriften mit Vorträgen oder einzelnen Vortragsreihen an Technischen Hochschulen begnügen. In Technik Voran, der Zeitschrift des RDT, forderte Schubert ungeachtet dessen bereits 1925 die Einrichtung von kolonialtechnischen Lehrstühlen, da die AKOTECH die „Aufgabe allein nicht bewältigen“ könne, die interessierte Jugend dementsprechend heranzubilden. ${ }^{129}$ Vor diesem Hintergrund hatte er beim verantwortlichen Geheimrat Gunzert vom Auswärtigen Amt um Beihilfe zu einer im Winter an der TH Charlottenburg stattfindenden kolonialtechnischen Vortragsreihe gebeten. ${ }^{130}$ Schuberts Bemühungen waren erfolgreich und so konnten im Wintersemester 1925/26 an der Hochschule unter dem Dach des dortigen Außeninstituts erstmals ${ }_{15}$ Vorträge angekündigt werden, die koloniale und technische Fragestellungen thematisierten. ${ }^{131}$ Als Referenten hatte man den technischen Publizisten Siegfried Hartmann, Geo A. Schmidt sowie den "kolonialpropagandistische[n] Veteran“132 Paul Rohrbach gewinnen können, wie auch den Geheimen Oberbaurat Franz Baltzer, ehemaliger Leiter der Abteilung für Bau- und Verkehrswesen sowie für technische Angelegenheiten beim RKA. Trotz dieser illustren Liste kolonialrevisionistischer Denker wies nur gut ein Drittel aller Vorträge einen expliziten

\footnotetext{
128 Foehr, Kolonialingenieur, 1910, S. 166; Foehr zufolge besuchten von 157 Personen gerade einmal fünf Ingenieure das Institut.

129 Schubert, Ausbildung von Kolonialtechnikern, 1925, S. 11.

13 AKOTECH an KORAG, 17.6.1925, BArchB, R 8023/377, fol. 149.

131 AKOTECH an Außeninstitut TH Berlin, BArchB, R 10o1/6738, fol. 152 f.; TH Berlin: Vorlesungsverzeichnis für das Studienjahr 1925/26; Berlin 1925.

132 Osterhammel, Aufstieg Asiens, 2017, S. 128.
} 
Zusammenhang zu kolonialen Fragestellungen auf. Die übrigen behandelten vor allem allgemeine verkehrstechnische Probleme in außereuropäischen Gebieten wie Mexiko oder China, die für den deutschen Export sowie die betroffenen Ingenieure an Bedeutung gewannen. ${ }^{133}$

Diese Themensetzung hatte durchaus taktische Gründe, da Themen der Exportsteigerung eine reale Nachfrage bedienten, die der Kolonialtechnik nicht gegenüberstand. Die als Ausschnitt bereits zitierte Einteilung von Ländern hinsichtlich ihres technischen Entwicklungsstandes nach Stritzel verdeutlicht, dass in „halbentwickelten Ländern“ es vor allem darauf ankomme, „am Aufbau der heimischen [asiatischen und südamerikanischen, S. B.] Industrie in einer für uns möglichst nutzbringenden Weise teilzunehmen“, wobei die erfüllendste Arbeit in den „völlig unentwickelten“ Kolonien liege. ${ }^{134}$ Die Vermischung der beiden verwandten Themenbereiche ist daher als Strategie zu sehen, die Kolonialtechnik im Rahmen von Vorträgen zu popularisieren.

Dank Franz Baltzer fand eben genau jener Teilbereich in Form einer Vorlesung zu "Klein- und Kolonialbahnen“ Mitte der 2oer-Jahre Eingang in das Curriculum des Studiengangs für Bauingenieurwesen an der TH Berlin ${ }^{135}$, blieb hier jedoch ohne größere Wirkung, bis sie mit dem Tod Baltzers 1926 als Kursinhalt gänzlich entfiel. ${ }^{136}$ Nachdem im Wintersemester 1926/27 keine kolonialtechnischen Vorträge stattgefunden hatten, nahm man diese Art der Öffentlichkeitsarbeit 1928 wieder auf und führte sie bis in die 3oer-Jahre hinein fort. ${ }^{137}$ Die dritte Vortragsreihe an der TH Berlin Ende der 1920er-Jahre richtete sich nun besonders an junge Ingenieure, die am Beginn ihrer beruflichen Laufbahn standen. Unter dem Motto „Die Technik in warmen und heißen Ländern“ waren die Referate jeweils einem von drei Schwerpunkten zugeordnet. Thematisch umfassten die Ausführungen hygienisch-medizinische sowie allgemein-ökonomische Kontexte. Der dritte und mit Abstand umfangreichste Teil war diesmal jedoch der Kolonialtechnik gewidmet. ${ }^{138}$

Im Rahmen dieser Wiederaufnahme der Vortragsreihe 1928 dachte Marinebaurat a. D. Erich Röhlke bereits an die Umwandlung jener externen Vorlesungen „in systematische Kurse für die Ausbildung von Ingenieuren, welche

\footnotetext{
133 AKOTECH an Außeninstitut TH Berlin, BArchB, R 1001/6738, fol. $15^{2}$ f. Zur vergleichbaren Position für China: Gransow, Maschinenexport, 1986, S. $181 \mathrm{f}$.

134 Stritzel, Tätigkeit des Ingenieurs, 193o, S. 199 f.

135 Die TH Charlottenburg wurde im Zuge der Eingemeindung der selbstständigen Gemeinde Charlottenburg zur TH Berlin umbenannt.

136 Vgl. Technische Hochschule Berlin, Vorlesungsverzeichnis 1924/25, 1924, S. 37; dies., Vorlesungsverzeichnis 1925/26, 1925, S. 41.

137 AKOTECH, Akotech-Hochschulvorträge (1927/28), 1929.

138 Röhlke, Vorwort, 193 o.
} 
ins Ausland gehen wollen“. Dieses Vorhaben, das er noch im selben Jahr persönlich mit dem Generalsekretär der DKG Erich Duems besprach, stieß bei jenem auf großen Zuspruch. Duems, der in diesem Jahr zum ersten Mal die Vortragsreihe zusammen mit Vertretern der AKOTECH durchführte, sprach sich sogar für die „Veranstaltung eines besonderen Kursus für Auslands- und Kolonialtechnik im Rahmen des Gesamtkurses“ aus. ${ }^{139}$

Solche Bestrebungen, die Kolonialtechnik im Rahmen eines ordentlichen Studienganges zu etablieren, sollten jedoch trotz der immer wieder geäußerten Unterstützung und Notwendigkeit vergeblich bleiben. In dieser Hinsicht positive Entwicklungen waren meist an Initiativen einzelner Professoren wie Franz Baltzer gebunden. Der Privatdozent für Tropen- und Siedlungstechnik an der TH Berlin, Wilhelm Keller, hielt in diesem Sinne im Sommersemester 1933/34 mit der „Wasserwirtschaft im Rahmen der Übersee- und Siedlungspolitik" nur eine Vorlesung, die einen kolonialtechnischen Schwerpunkt setzte, konnte sein Angebot in den Folgejahren jedoch weiter ausbauen. Zusätzlich zur Veranstaltung „Bauen und Siedeln im warmen Klima, Bauhygiene (Aufgaben des Auslandsingenieurs)“ bot er ein „Auslandstechnisches Kolloquium“ sowie weitere kolonialtechnische Übungen an, in denen die Studierenden relevante Fertigkeiten erlernen konnten. Doch auch dieses Angebot wurde in den Folgejahren wieder deutlich zurückgefahren. ${ }^{140}$

Richard Csaki, Leiter des Deutschen Auslandsinstituts und seit 1940 Dozent für Auslandskunde an der Universität Tübingen, strebte im September 1933 in Zusammenarbeit mit dem Stuttgarter Oberbürgermeister Karl Strölin die Einrichtung eines Instituts für ,Tropentechnik` an der TH Stuttgart an. ${ }^{141} \mathrm{Als}$ Leiter wollte man jenen Professor Keller anwerben, der zu diesem Zeitpunkt noch in Berlin tätig war. Ein weiterer diesbezüglicher Vorstoß sollte drei Jahre später von Erziehungsminister Rust mit der Begründung abgelehnt werden, dass ein Institut zur Ausbildung von Auslandsingenieuren bereits seit dem vorangegangenen Jahr an der TH Aachen in der Art eines Zusatzstudiums existiere. Folgt man den Ausführungen Thomas Müllers, so orientierte sich die Ausbildung dieser Auslandsingenieure weniger an den Anforderungen der Exportwirtschaft, sondern vor allem an den nationalsozialistischen

139 AKOTECH an DKG, 23.7.1928, BArchB, R 8o23/377, fol. 27.

140 Der in Stuttgart geborene Hermann Keller (1895-1970) hatte jene Stellung zwischen 1929 und 1936 an der TH Berlin inne: Catalogus Professorum. Professorinnen und Professoren der TU Berlin und ihrer Vorgänger, https://cp.tu-berlin.de/person/1929 [Zugriff: 20.6.2019]; vgl. Technische Hochschule Berlin, Vorlesungsverzeichnis, 1932/33, S. 97; ebda., 1934/35, S. 141 f.; ebda., 1935/36 [Zugriff: 20.6.2019].

141 Folberth, Csaki, Richard, 1957, S. 434 f. [Zugriff: 10.6.2019]. 
Raumordnungsideen. ${ }^{142}$ Diesbezüglich hatte man in Stuttgart erfolglos versucht, den verantwortlichen Dozenten Dr. Gustav Plessow aus Aachen abzuwerben. Nichtsdestotrotz war dem amtierenden Stuttgarter Rektor Stortz 1938 noch immer an der Einrichtung eines solchen Instituts gelegen, nun aber unter der Leitung der AKOTECH. Doch auch dieses Vorhaben blieb letztlich erfolglos. ${ }^{143}$ Röhlke hatte diesen Versuch im Mai 1938 noch mit der Veröffentlichung zweier Artikel in bekannten technischen Fachzeitschriften, in Technik und Kultur sowie nur einen Monat später in der Verkehrstechnischen Woche flankiert. ${ }^{144}$

Ähnlich dem Stuttgarter Vorbild plante man Ende der 3oer-Jahre auch in Hamburg die Einrichtung eines Instituts für Kolonialingenieure. Das Studium sollte aus einem dreisemestrigen Grundkurs bestehen, der im Rahmen einer Spezialisierung über zwei Semester die Ingenieure auf ihre spätere Tätigkeit vorbereitete. Das Kolonialinstitut, an dem die Einrichtung des Kurses geplant war, wollte damit an die eigene Gründungstradition des Jahres 1908 anknüpfen. Im Mai 1939 wurde das Institut offiziell eröffnet. Aus Hamburger Sicht schien man dafür besonders durch die große Zahl der ansässigen, im Überseehandel tätigen Firmen prädestiniert und auch die Abteilung des VDI vor Ort entschloss sich zur Gründung eines kolonialtechnischen Arbeitskreises. ${ }^{145}$ Das Kolonialinstitut, gut 40 Personen unterschiedlichster Fachrichtungen, war bemüht, die ganze Bandbreite kolonialen Wissens abzudecken. Im Falle eines erfolgreichen Ausgangs des Krieges fasste man sogar die Gründung einer eigenständigen Kolonialuniversität ins Auge. Unter den 1940 beantragten vier Lehrstühlen befand sich jedoch keiner mit einer technischen Ausrichtung. Jegliche Unternehmungen in dieser Richtung wurden letztlich 1943 auf Weisung des Reichsstatthalters in Hamburg, Karl Kaufmann, eingestellt. ${ }^{146}$

Deutlich erfolgreicher verlief die Etablierung anderer kolonialer Fachbereiche wie der Tropenmedizin oder der Kolonialgeografie. ${ }^{147}$ Nichtsdestotrotz lässt sich an den aufgeführten Versuchen und Teilerfolgen, die

\footnotetext{
142 Müller, Ausgangsstellung zum Angriff, 2003, S. $833 \mathrm{f}$.

143 Voigt, Universität Stuttgart, 1981, S. 44 f.; Kalkmann, Technische Hochschule Aachen, 2003, S. 285-287; Müller, Ausgangsstellung zum Angriff, 2003, S. 833 f.

144 Röhlke, Ausbildung und Fortbildung, 1938; Röhlke, Institut für Kolonial- und Tropentechnik, 1938.

145 Linne, Renaissance, 2004, S. 136-138; Linne, Deutschland jenseits, 2008, S. 120 f. Schon 1922 hatte sich in Hamburg ein „Ausschuss für Auslands- und Kolonialkunde“ gegründet: Brahm/Jochen, Auslandswissenschaften, 2006, S. 269.

146 Vgl. Linne, Renaissance, 2004, S. 140 f., 159.

147 Zur Kolonialgeografie vgl. Gräbel, Erforschung der Kolonien, 2015; in diesem Sinne auch die auf Carl Uhlig zurückgehende Etablierung von Studienschwerpunkten wie der
} 
Auslands- beziehungsweise die Kolonialtechnik als eigenständiges Studienfach zu etablieren, durchaus ein Prestigegewinn dieses Bereichs konstatieren. Tatsächlich existierte zu Kriegsbeginn an der TH Aachen bereits ein Seminar für Auslandsingenieure unter der Leitung von Gustav Plessow. Hierbei handelte es sich jedoch weniger um einen eigenständigen Studiengang als um eine Art Zusatzqualifikation über vier Semester, die sich speziell an Ingenieure richtete, die eine Tätigkeit in den Tropen beziehungsweise Kolonien anstrebten. ${ }^{148}$ War Plessows Ausrichtung eines Seminars für Auslandsingenieure anfangs aus seiner Angst geboren, bei zu geringem Interesse an seinen angebotenen Seminaren seine Beschäftigung zu verlieren, und gleichsam an sein Versprechen geknüpft, durch die Akquise interessierter Industrieunternehmen die Einrichtung kostenneutral zu gestalten, veränderten sich die Voraussetzungen entscheidend. Anfang der 4oer-Jahre wurden Plessows Forschungen und Lehre als so wichtig und prestigeträchtig betrachtet, dass er sogar ohne die Einreichung einer gesonderten wissenschaftlichen Arbeit habilitiert wurde. ${ }^{149}$

Ganz ähnlich deuteten auch die „alten Kolonialleute“, gerade Ingenieure wie Schubert, eine zunehmende Etablierung und Institutionalisierung der Kolonialtechnik als Statuserhöhung der eigenen Profession. ${ }^{150}$ Diese Entwicklung war in der Weimarer Republik eng mit der Hoffnung verknüpft gewesen, das von Vertretern der technischen Profession bemängelte Juristenmonopol in der Verwaltung zu brechen. ${ }^{151}$ Schubert verwies auf den Umstand, dass nur Juristen ins Reichsministerium für Wiederaufbau aufgenommen worden waren. ${ }^{152}$ Er selbst wurde nach dem Krieg im Reichsausgleichsamt beschäftigt. Besonders kritisierte er diese Praxis vor dem Hintergrund, dass der ehemalige Gouverneur Seitz bei der Enthüllung eines Kolonialdenkmals im großen Sitzungssaal des RKA die schnelle koloniale Erschließung als Ergebnis des Zusammenwirkens von Technikern, Ärzten und Erziehern gewürdigt habe und man daher dem Ingenieur seinen verdienten Platz im Staat und in der Verwaltung nicht verweigern dürfe. ${ }^{153}$

„Kolonialgeographie“ oder der „Auslandskunde“ in Tübingen: Daniels, Auslandskunde, 2010, S. 357-365; vgl. auch Zimmerer, Birth of the Ostland, 2005, S. 216.

148 Vgl. Anonymus, Seminar für Auslandsingenieure, 1942.

149 Kalkmann, Technische Hochschule Aachen, 2003, S. 28 5-287.

15 O Vgl. Schubert, Technik in den deutschen Schutzgebieten, 1926, S. 139.

151 Vgl. u. a. Anonymus, Betreff Vorschlag Wangelin, 1919; Speier, Die Angestellten vor dem Nationalsozialismus, 1977, S. 109.

$15^{2}$ Vgl. zur Geschichte dieser Einrichtung: Hainbuch, Reichsministerium für Wiederaufbau, 2016.

153 Vgl. Schubert an KORAG, Juni 1924, BArchB, R 10o1/6738, fol. $5 \mathrm{f}$. 
Neben den Bestrebungen, die Kolonialtechnik als Studienfach oder zumindest als Zusatzqualifikation in die technische Hochschulbildung zu integrieren, lässt sich noch ein zweiter Entwicklungspfad identifizieren, der ein ganz ähnliches Ziel verfolgte. Dieser eher praktische Ansatz war eng an die Initiative einzelner Politiker der NSDAP geknüpft. Der war es bereits vor den entscheidenden Wahlen der 193oer-Jahre gelungen, sich als eine Partei zu profilieren, die der Technik und damit auch den Ingenieuren jenen Platz in der Gesellschaft zubilligte, den sie ihrer Wahrnehmung nach verdienten. Der Ingenieur Schwerber versprach bereits 1930, als „erste[s] Zeichen dieser im Dritten Reich grundsätzlich veränderten Stellung des Staats zur Technik [.] die sofortige Errichtung eines großen zentralen Ministeriums der Technik ${ }^{\star 154}$ und griff damit eine der zentralen Forderungen technokratisch orientierter Organisationen wie des RDT auf. ${ }^{155}$ Auch mit Blick auf die als ungerechte Herabsetzung empfundene Unterordnung der Techniker und Ingenieure unter Ökonomen und dem von diesen vertretenen Postulat der Wirtschaftlichkeit, sprach Schwerber dem "heute [1930, S. B.] dominierende[n] ,Wirtschafts'ministerium“ lediglich „die ihm von Rechtswegen allein zukommende Stellung eines untergeordneten Ressorts" zu. ${ }^{156}$

Es wäre dennoch überzogen und würde die realen Verhältnisse nicht widerspiegeln, die technische Berufsgruppe in Gänze als besonders empfänglich für die Politik der Nationalsozialisten darzustellen. ${ }^{157}$ Dennoch, und daran besteht kein Zweifel, gelang es einzelnen Akteuren, darunter einer beachtlichen Zahl von ehemaligen Kolonial- und Auslandsingenieuren, hohe Verwaltungsposten im nationalsozialistischen Regime zu bekleiden. ${ }^{158}$ Die Institutionalisierung eines eigenständigen Studien- und Ausbildungsganges für koloniale Nachwuchskräfte wurde staatlicherseits vorangetrieben. Eine herausragende

154 Der RDT hatte in seiner Fachzeitschrift gar dazu aufgerufen, all jenen Parteien die Stimme und Unterstützung zu versagen, die sich den Forderungen des Reichsbundes nach mehr Mitsprache und Entscheidungsgewalt der Ingenieure in den Verwaltungen widersetzten: Verlohr/Gerstenberg, Wahlaufruf, 1929, S. 15; vgl. Schwerber, Der berufsständische Gedanke, 1930, S. 11 f. Im Vorfeld zu diesem Artikel wurden verschiedene Parteien über ihr Verhältnis und ihre Ziele im Hinblick auf die Technik und die Ingenieure befragt, die Antworten wurden in jenem Artikel gedruckt.

155 Vgl. für die seit 1919 vom RDT wiederholt propagierte Forderung nach einem Technikministerium u. v. m.: Feßler, Schaffung eines Ministeriums, 1919, S. 7; Vr., Technischer Staatssekretär, 1926.

${ }_{15} 6$ Schwerber, Der berufsständische Gedanke, 1930, S. $11 \mathrm{f}$.

157 Vgl. Ludwig, Technik und Ingenieure, 1979, S. 57; Willeke, Technokratiebewegung, 1995, S. 212.

158 Vgl. dazu Kapitel 4.4 Postkoloniale Karrieren. 
Stellung nahm dabei eine Arbeitsgemeinschaft ein, die ihr besonderes Augenmerk auf das koloniale Verkehrswesen gelegt hatte.

Noch vor Ausbruch des Zweiten Weltkrieges trafen sich im Berliner Reichsverkehrsministerium mehrere hochranginge Ingenieure zur ersten Sitzung der Arbeitsgemeinschaft über koloniales Verkehrswesen mit dem Ziel, einen Arbeitsplan zu entwerfen. Vorsitzender dieser Arbeitsgemeinschaft war Julius Dorpmüller (1869-1945), Direktor der Reichsbahn und seit 1937 Reichsverkehrsminister. Dem Gremium gehörten neben Staatssekretär Kleinmann, Reichsleiter des KPA, auch Ritter von Epp, der durch seinen 1928 erfolgten Eintritt in die NSDAP eine frühe personelle Verbindung mit der Kolonialbewegung schuf, und der ehemalige Gouverneur für DSWA, Friedrich von Lindequist, an. ${ }^{159}$ Der Kolonialingenieur und Geheime Baurat Franz Allmaras war als Obmann der Arbeitsgemeinschaft für das Gebiet Ostafrika verantwortlich, Direktor Semke für Kamerun und Togo und Gouverneur a. D. Dr. Hahl für die Südsee-Gebiete. Der ebenfalls im kolonialtechnischen Kontext erfahrene Baurat Reh, der für DSWA zuständig war, musste dem Treffen krankheitsbedingt fernbleiben. ${ }^{160}$

Die Berufung der benannten Obmänner war von Dorpmüller, Lindequist und Ritter von Epp bereits einen Monat zuvor während eines konstituierenden Treffens der Arbeitsgemeinschaft in München beschlossen worden. ${ }^{161}$ Auch Minister Dorpmüller konnte als Ingenieur auf eine koloniale Vergangenheit verweisen. Anlässlich eines Vortrages bei der DKG berief er sich auf seine Erfahrungen beim chinesischen Bahnbau und auf "lange Jahre“, die er „draußen gelebt" habe. ${ }^{162}$ Die Arbeitsgemeinschaft für koloniales Verkehrswesen sollte durch die Hinzuziehung von weiteren Fachleuten um die vordefinierten Bereiche Eisenbahnwesen, Straßen und Kraftverkehr, Schifffahrt, Häfen sowie Luftfahrt für die jeweiligen Kolonien erweitert werden. Das Eisenbahnwesen sah man dabei als den wichtigsten und umfangreichsten Punkt an, der von den jeweiligen Obmännern persönlich zu betreuen sei. Für den Fachbereich der Straßen wollte man Karl Krüger, ebenfalls Mitglied der AKOTECH, gewinnen. ${ }^{163}$

Während des Treffens im Februar 1939 besprachen die Anwesenden auch Allmaras Bericht über das Koloniale Verkehrswesen. Dieser enthielt die wiederholte Forderung nach Rückgabe der deutschen Kolonien und argumentierte

\footnotetext{
159 Hildebrand, Reich zum Weltreich, 1969, S. 115-119.

16 o Besprechung, 27.2.1939, S. 1, BArchB, R 1001/9664.

161 Ebda., S. $1 \mathrm{f}$.

162 Dorpmüller, Eisenbahnbau in China, 1928, S. 1140. Zur Biografie Dorpmüllers vgl. Gottwaldt, Reichsverkehrsminister, 2004, S. 145 f.; Gottwaldt, Deutschlands Sieg, 1995, S. 154-156.

163 Besprechung, 27.2.1939, S. 4, BArchB, R 1001/9664.
} 
seinerseits mit der fehlenden infrastrukturellen Entwicklung seit dem Ende der deutschen Kolonialherrschaft. ${ }^{164}$ Diese Sichtweise wurde in einem Bericht vom August desselben Jahres nochmals bekräftigt, in dem man unter anderem den Ausbau der Kolonialbahnen während und nach der deutschen Kolonialzeit verglich. Allmaras hob darin hervor, dass die bereits 1914 vorhandenen fast viereinhalbtausend Schienenkilometer in den Jahren bis 1937 lediglich um 1.20o Kilometer ergänzt worden waren. Aus diesen Zahlen begründete er nicht nur die deutsche Kolonisationsfähigkeit, sondern auch die wiederholte Forderung nach "Rückgliederung“ der ehemals deutschen Schutzgebiete. ${ }^{165}$ Diese Argumentation wendete die der deutschen Kolonialverwaltung vonseiten der Kolonialmächte Frankreich und Großbritannien zugeschriebene „Unfähigkeit zur Kolonisation“ ihrerseits gegen die beiden Großmächte. ${ }^{166}$ Folgt man dieser Argumentation, so fand die Fähigkeit zur Kolonisation ihren Ausdruck in der Planung und Errichtung technischer Transportinfrastruktur mit dem Ziel, die Kolonien zu erschließen.

Es mag durchaus überraschen, wie detailliert einige der Pläne zur Wiedereinrichtung einer deutschen Kolonialherrschaft bereits vor Kriegsbeginn ausgearbeitet waren. Die Aufstellung wies allein für DOA einen notwendigen Stamm von 500 Beamten aus, wovon gut zehn Prozent auf den kolonialen Autobahn-, Wege- und Brückenbau entfielen. ${ }^{167}$ Geheimrat Theodor Gunzert vom Auswärtigen Amt verbrachte selbst mehr als ein Jahrzehnt in DOA, davon die meisten Jahre als Bezirksamtmann im Ort Mwanza am Viktoria-See und war Ende der 3oer-Jahre maßgeblich an der Aufstellung der Dienststellenplanung für DOA beteiligt. Er konstatierte einen Bedarf von nicht weniger als ${ }_{167}$ Personen für die geplante ostafrikanische Bauverwaltung, davon 2o Bauräte und fast 25 Bauamtmänner und Inspektoren, also annähernd 5 o Personen mit technischer Hochschulbildung. Zwar umfasste diese Planung bereits die Eisenbahnkommissare, doch gab Gunzert zu bedenken, dass für die derzeit vorhandenen Eisenbahnen, sofern diese nicht privat betrieben werden sollten, nochmals 15 o Ingenieure und Techniker im Rahmen einer „selbstständige[n] Eisenbahnabteilung" benötigt würden. ${ }^{168}$

\footnotetext{
164 Allmaras, Koloniales Verkehrswesen (geheim), BArchB, R 1001/9664.

165 Dorpmüller, Arbeitsgemeinschaft Kamerun/Togo, August 1939, BArchB, R 5/23268, fol. 55,81 .

166 Baer/Schröter, Kopfjagd, 2001, S. 170; Schnee, Koloniale Schuldlüge, 1924. Für den Versuch, diese Anschuldigungen durch koloniale Arbeit zu entkräften, vgl. Ausstellungsamt der Landeshauptstadt Dresden, Ausstellungsführer, 1939, S. 26.

${ }_{167}$ Zusammenstellung erforderlicher Beamter (DOA), 20.3.1939, BArchB, NS $5^{2} / 47$, fol. 34 .

168 Gunzert, Dienststelle DOA, ebda., fol. 81-91.
} 
Bereits im März 1939 war General Ritter von Epp damit beauftragt worden, ein Reichskolonialamt aufzubauen. Im Zuge der französischen Niederlage im Sommer 1940 erhielten diese kolonialrevisionistischen Pläne verstärkt Auftrieb, sodass die „Arbeiten für unsere künftige Kolonialverwaltung“ forciert wurden. ${ }^{169}$ Mit der teils recht detaillierten Ausarbeitung sowie der Zusammenführung aller Berichte und Planungen durch die Vorsitzenden der jeweiligen Fachbereiche betrachtete der Leiter des KPA der NSDAP, von Epp, diese Arbeit für den Verkehrsausschuss im April 1940 vorerst als beendet. ${ }^{170}$ Solche Vorbereitungen waren vom Mitbegründer der AKOTECH, Alfred Andreas Schubert, bereits Mitte der 192oer-Jahre unter dem Schlagwort „technischer Mobilmachungsplan" wiederholt gefordert worden. ${ }^{171}$

Ganz im Sinne einer verstärkten kolonialen Vorbereitungsarbeit und mit Blick auf die französischen Kolonien bekundete auch Fritz Todt, unter anderem Reichsminister für Bewaffnung und Munition, gegenüber von Epp sein Interesse am Aufbau einer „kolonialen Bauverwaltung", wobei er vor allem die Auswahl und Schulung infrage kommender Bewerber im Auge hatte. ${ }^{172}$ Nach eigener Überzeugung habe er, Todt, in seiner Stellung als Generalinspektor für das deutsche Straßenwesen mit der Entsendung von Beamten nach Afghanistan zwei Jahre zuvor bereits die Gelegenheit ergriffen, „deutsche Ingenieure für den Kolonialdienst zu schulen.“ Da sich jene „für Arbeiten unter primitiven Verhältnissen glänzend bewährt" hätten, sollte sich ein Teil der zukünftigen Kolonialingenieure aus dieser afghanischen „Stamm-Mannschaft“ rekrutieren. ${ }^{173}$

Mit der benannten Gelegenheit bezog er sich auf das Abkommen über Zusammenarbeit beim Straßenbau in Afghanistan vom 18. Oktober 1937, das auch unter seinem Namen als „Dr. Todt-Abkommen“ firmierte. ${ }^{174}$ Glasneck und Kircheisen sprechen in diesem Zusammenhang vom Verwaltungsabkommen über die Entsendung deutscher Ingenieure nach Afghanistan. ${ }^{175}$ Bestandteil der Vereinbarung war die Entsendung eines deutschen Generalingenieurs sowie mehrerer Oberingenieure sowohl nach Kabul als auch in einzelne afghanische

169 Lammers an Oberste Reichsbehörden, 22.6.1940, BArchB, R 46o1/1119, fol. 1; Linne, Deutschland jenseits, 2008, S. 75, 79 .

170 Dorpmüller an Krüger, 5.4.1940, BArchB, R 5/23268, fol. 1.

171 AKOTECH an KORAG, 9.10.1924, BArchB, R 8023/377, fol. $212 \mathrm{f}$.

172 Vgl. Ludwig, Technik und Ingenieure, 1979, S. $196 \mathrm{f}$.

173 Todt an Ritter von Epp, 22.6.1940, BArchB, R 46o1/1119, fol. 5 f.

174 Boelcke, Deutschlands politische und wirtschaftliche Beziehung, 1969, S. 18o. Zudem lassen sich auch eine kurze Erwähnung des „Todt-Abkommens“ sowie eine ausführliche Schilderung der damit im Zusammenhang stehenden Waffenexporte finden: Boelcke, Deutschland als Welthandelsmacht, 1994, S. 87-89, 199 (hier FN 109).

175 Kircheisen/Glasneck, Türkei und Afghanistan, 1968, S. 193. 
Distrikte. Die entsandten Personen berieten die lokale Regierung als technische Experten in allgemeinen Fragen des Bauwesens, besonders aber hinsichtlich des Ausbaus der hiesigen Infrastruktur. Die technische Ausbildung in Afghanistan fand auf deutscher Seite ebenso finanzielle wie personelle Unterstützung. Mit Trautmann wurde 1938 ein deutscher Ingenieur Direktor des einzigen Technikums in Afghanistan in Kabul, der hier zusammen mit zehn entsandten Lehrern unterrichtete. ${ }^{176}$

Die ersten Techniker und Ingenieure, für die in den ausgehenden 193oerund beginnenden 4oer-Jahren ein eindeutiges Interesse an einer kolonialen Tätigkeit in Afrika außerhalb der erwähnten kolonialrevisionistischtechnischen Zeitschriften dokumentiert ist, lassen sich jedoch nicht jener afghanischen "Stamm-Mannschaft" zuordnen. Wie Bewerbungen und diesbezügliche Aktenvermerke beweisen, reichte das Interesse über diesen engen Kreis hinaus. Da im Sommer 1940 einheitliche Richtlinien und Voraussetzungen für Ingenieure zur Bewerbung im Kolonialdienst nicht vorlagen, erkundigten sich die Interessenten bei unterschiedlichen amtlichen Stellen nach Möglichkeiten, in den Kolonialdienst einzutreten. ${ }^{177}$

Der Diplom-Ingenieur Gebhard Himmler, verantwortlich für Berufsfragen der technischen Profession, bemerkte hinsichtlich einer dieser Anfragen in einer Aktennotiz, dass es bisher keine solche Stelle gäbe, bei der sich Techniker oder Ingenieure melden könnten, er die Anfrage aber gern an das KPA weiterleite. ${ }^{178}$ Der beim KPA zuständige Geheimrat Heilingbrunner bemerkte, dass hierfür tatsächlich noch keine Richtlinien ausgearbeitet worden seien und er den Personalbedarf nicht abschätzen könne. Interessierte Ingenieure, die sich mit ihren Gesuchen an das KPA in Berlin und hier an das Amt für Planung zu wenden hätten, würden jedoch vermerkt. ${ }^{179}$ Auch Gebhards Bruder, der Reichsführer-SS Heinrich Himmler, hatte 1937 damit begonnen, geeignete Bewerber der Schutzstaffel auszuwählen, die einer kommenden

${ }_{17} 6$ Kircheisen/Glasneck, Türkei und Afghanistan, 1968, S. 193., S. 193-201; Boelcke, Deutschland als Welthandelsmacht, 1994, S. 180-182; Rohmeder, Deutsche in Afghanistan, 1938, S. 106-108. Vgl. zu den am Technikum angestellten deutschen Lehrern u. a. das Arbeitszeugnis des Ingenieurs Heinz Hofmann, der zwischen Dezember 1937 und Oktober 1941 in Kabul tätig war: Arbeitszeugnis, Heinz Hofmann, PA AA, RAV Kabul II.

177 Vgl. NS Gauleitung (Haller) an Hauptamt für Technik, 29.6.1940, BArchB, NS 14/24; Kolonialeinsatz (von Schönleben), 11.9.1940, BArchB, R 46o1/1119, fol. 7; Kolonialer Straßenbau (von Schönleben), 9.9.1940, ebda., fol. 8.

178 Notiz: Kolonialeinsatz, 17.8.1940, BArchB, NS 14/24; auch Ludwig, Technik und Ingenieure, 1979, S. 199.

179 Kraus an Himmler, 6.11.1940, ebda. 
kolonialen Landespolizei angehören sollten. ${ }^{180}$ Heilingbrunners Hinweis, dass man zum gegenwärtigen Zeitpunkt noch nicht sagen könne, wie viele Ingenieure gebraucht würden, lässt die Frage aufkommen, wie reibungslos der Informationsaustausch zwischen den einzelnen Stellen des KPA ablief. Wie mit dem Verweis auf die Planungen für eine zukünftige ostafrikanische Baubehörde aufgezeigt wurde, gab es durchaus Schätzungen über den angenommenen Bedarf an technischen Kräften für ein deutsches Kolonialreich in Afrika. ${ }^{181}$ Ebenso hatte die AKOTECH mehrmals angeboten, die Vermittlung von willigen Ingenieuren in den Auslands- und Kolonialdienst zu übernehmen.

Zum Ausgangspunkt weiterer Entwicklungen im Bereich der Ausbildung von Kolonialingenieuren wurde die Anfang Dezember 1940 in Stuttgart abgehaltene Kolonialtechnische Arbeitstagung des VDI, auf der auch die eingangs vorgestellte Arbeitsgruppe Kolonialstraßenbau zu ihrer konstitutiven Sitzung zusammentrat. ${ }^{182}$ Die Gesellschaft konnte auf einen hochkarätigen Teilnehmerkreis verweisen. Unter den mehr als 800 Zuhörern befanden sich neben Todt als Schirmherr der Veranstaltung und dem Ministerialrat Dorsch, mit Professor Huber und Loos auch etablierte Akademiker Technischer Hochschulen sowie Vertreter der organisierten Kolonialtechnik: Baurat a. D. Reh vom KWK, Direktor Semke von Lenz \& Co sowie Stussig und Esterer von der AKOTECH. ${ }^{183}$

Bereits bei diesem ersten Treffen sprach sich Todt für eine enge Zusammenarbeit mit der Bauindustrie aus, um geeignete Ingenieure ausfindig zu machen, die neben ihrer technischen Ausbildung über „zusätzliches Spezialwissen für koloniale Verhältnisse" verfügten. Ob er damit auf die im Zuge seines mit der afghanischen Regierung geschlossenen Abkommens entsandten Ingenieure abhob, bleibt ungewiss. Todt hielt es für notwendig, potenziellen Kandidaten eine besondere Weiterbildung zu ermöglichen. Diese sollte aus vierteljährlich stattfindenden Kursen im Umfang von drei bis vier Tagen im Schulungsheim des Nationalsozialistischen Bundes deutscher Technik (NSBDT) in Plassenburg bestehen. Zudem regte er ein Abkommen mit der italienischen Regierung an, um interessierten Ingenieuren das Sammeln praktischer

\footnotetext{
180 Hildebrand, Reich zum Weltreich, 1969, S. 569, 585. Das KPA plante die Aufstellung einer „Polizei-Truppe“ für die Kolonien sowie das Oberkommando der Wehrmacht die einer „Schutztruppe“: ebda. S. 597.

181 Vgl. dazu nochmals Zusammenstellung erforderlicher Beamter (DOA), 20.3.1939, BArchB, NS 52/47, fol. 34 .

182 Linne, Deutschland jenseits, 2008, S. 120 f.; Arbeitsgruppe „Kolonialstraßenbau“, 3.12.1940, BArchB, R 46o1/1119, fol. 12-21.

183 Ebda.; Seidler, Fritz Todt, 1988, S. 142 f.
} 
Erfahrung im italienisch besetzten Norden Afrikas zu ermöglichen. Italien schien dafür besonders geeignet, da sämtliche Teilnehmer der Tagung den italienischen Straßenbau in Afrika als vorbildlich rühmten. ${ }^{184}$ Letztlich einigte sich die Arbeitsgruppe darauf, die „Aufstellung eines Schulungsplanes für die Vorbildung von Kolonial-Ingenieuren" als Zielstellung in ihr Arbeitsprogramm aufzunehmen. ${ }^{185}$

Wenige Wochen später begrüßte Todt in einem Schreiben zwar diese Entwicklung, die er selbst mit angeregt hatte, bemängelte aber zugleich, dass solche Zusammenkünfte zu selten stattfänden und dann lediglich im Rahmen größerer Veranstaltungen wie eben im Dezember 1940 in Stuttgart. Dies sei jedoch unzureichend, weshalb er forderte, „dass der Generalbevollmächtigte für die Regelung der Bauwirtschaft in Zusammenarbeit mit der Fachgruppe Bauwesen eine intensive Vorbereitung deutscher Kolonialingenieure einleitet." Neben der formalen Zustimmung der Arbeitsgruppe hin zu einem teilweise formalisierten Bildungsweg für Kolonialingenieure habe die kolonialtechnische Veranstaltung des VDI in seinen Augen aber vor allem gezeigt, „wie wenig der deutsche Ingenieur von den Schwierigkeiten des Schaffens im Kolonialraum heute weiß“. Das beabsichtigte der Minister zu ändern. ${ }^{186}$

Nimmt man Todts Aussagen ernst, so stellte dies eine Bankrotterklärung für all jene Kreise dar, die sich wie die AKOTECH bereits seit gut anderthalb Jahrzehnten der Aufgabe annahmen, kolonialtechnisches Wissen und Erfahrung zu sammeln und zu verbreiten. Die Zeitschrift Der Kolonialdeutsche monierte bereits 1924 im Umfeld der Gründung der AKOTECH die einseitig spezialisierte Ausbildung der Ingenieure an den deutschen Hochschulen und prophezeite eine „wirtschaftliche Katastrophe“, sollten dieselben nicht über ein für die Kolonien benötigtes, breites, technisches Allgemeinwissen verfügen. ${ }^{187}$ Und doch verwies Remy, als Leiter der Hauptabteilung IV im KPA, die für den technischen Bereich zuständig war, noch 1937 in einem kolonialpropagandistischen Artikel auf die „wohlvorbereitete Technikerschaft", die darauf wartete, in zukünftigen deutschen Kolonien tätig zu werden. ${ }^{188}$

Den bisherigen Ausführungen zufolge kann Fritz Todt durchaus ein gewisses Interesse für den Bereich der Kolonialtechnik beziehungsweise des kolonialen Bauwesens zugesprochen werden. Er ordnete beispielsweise an, die

\footnotetext{
184 Vgl. Anonymus, Aus der Arbeit der Akotech, 1941, S. 16; Arbeitsgruppe „Kolonialstraßenbau“, 3.12.1940, BArchB, R 4601/1119, fol. 16 f.; Linne, Deutschland jenseits, 2008, S. 112.

185 Arbeitsgruppe „Kolonialstraßenbau“, 3.12.1940, BArchB, R 46o1/1119, fol. 20 f.; Anonymus, Arbeitsgruppe Kolonialstraßenbau, 1941.

186 Todt an Schönleben, Dorsch und Schulze-Fielitz, 21.12.1940, BArchB, R 4601/1119, fol. $32 \mathrm{f}$.

187 Artikel in Der Kolonialdeutsche, ca. 1924, BArchB, R 1001/6738, fol. 181.

188 Remy, Zukunft des Schienenweges, 1937, S. 768.
} 
angestellten Techniker und Ingenieure sämtlicher Straßenbauverwaltungen sowie der "Organisation Todt" hinsichtlich einer möglichen Beschäftigung in den Kolonien zu befragen und Interessenten dazu aufzufordern, ihren ausgefüllten Personalbogen einzusenden. Die Ministerialdirektoren Dorsch, "Sonderbeauftragter für die kriegsmäßige Führung" in der Organisation Todt, und Schönleben, Leiter der Fachgruppe „Bauwesen“ im NSBDT, sollten in diesem Zusammenhang diejenigen bestimmen, die für die Sichtung der Bewerbungen zuständig wären und eine Auswahl von zwei- bis dreihundert Personen zur Prüfung ihrer Tauglichkeit an das Hamburger Tropeninstitut überweisen. Schließlich sei aus dieser Gruppe der „Tauglichen“ ein Obmann zu bestellen, „der diese Kolonialingenieure organisatorisch führt und zusammenhält“. Hinzu kämen dann noch regelmäßige Besuche von Kursen entweder auf der Plassenburg oder am Kolonialinstitut in Hamburg. ${ }^{189}$

Todts Anweisungen Folge leistend, rief die Fachgruppe „Bauwesen“ im NSBDT zu Beginn des Jahres 1941 in einem Schreiben an die Mitglieder des Bundes der Ingenieure und Architekten dazu auf, sich für den Kolonialdienst zu melden: „Für den Einsatz in den Kolonien werden besonders Männer gebraucht, die nach dem Weltkrieg noch in ehemaligen Kolonien oder anderen tropischen oder subtropischen Ländern tätig waren. ${ }^{190}$ Die in den 1940er-Jahren bereits betagten erfahrenen Kolonialingenieure, allen voran die Regierungsbaumeister der Kaiserzeit, schloss dieses Schreiben dabei indirekt aus. Für eine Entsendung kamen nur die Geburtsjahrgänge ab 189o in Betracht und dies auch nur bei Bestätigung ihrer kolonialen Erfahrung. Ansonsten zielte das Schreiben lediglich auf diejenigen ab, die nach 1900 geboren waren, um den besonderen körperlichen Anstrengungen vor Ort Rechnung zu tragen. ${ }^{191}$ Koloniale Erfahrung in deutschen Schutzgebieten konnten jedoch nur solche nach 1890 geborenen Ingenieure aufweisen, die ohne akademischen Abschluss in die Kolonien entsandt worden waren. Ausgehend von einer letztmöglichen Ausreise 1914 und dem frühestmöglichen Geburtsjahr 189o, wären die Techniker und Ingenieure zum Zeitpunkt der Entsendung 24 Jahre oder jünger gewesen - ein Alter, das Diplom-Ingenieure vor allem aber Regierungsbaumeister bei ihrem Hochschulabschluss bereits überschritten hatten. Der Reichsbahndirektionspräsident Karl Remy hatte einige Jahre zuvor auf dieses Problem hingewiesen:

189 Todt an Schönleben, Dorsch und Schulze-Fielitz, 21.12.1940, BArchB, R 46o1/1119, fol. 32 f.; Seidler, Fritz Todt, 1988, S. 142 f.

190 NSBDT, Bauwesen, 1.2.1941, BArchB, NS 14/25.

191 Ebda. 
Noch einige Jahre werden vergehen, dann legen die letzten Berufskameraden von der Reichsbahn, die einst den Weg in die deutschen Kolonien als Pioniere des deutschen Eisenbahnbaues gefunden hatten, ihre Arbeit nieder. Tropendienstfähig ist wohl heute dem Alter nach schon keiner dieser Männer mehr. ${ }^{192}$

Fehlende Kolonialerfahrung ließ sich jedoch, den gegebenen Rahmenbedingungen folgend, mit jugendlicher Gesundheit und klimatischer Resistenz substituieren. Eine Gleichung, die auf den 1940 ausgearbeiteten Richtlinien für die Vormerkung von Personen für den Kolonialdienst basierte. ${ }^{193}$

In den Richtlinien unterschied man zwei Gruppen von Anwärtern, den „Kolonialkenner“ und den „Nichtkolonialkenner“. Der ersten Gruppe wurde zugerechnet, wer mindestens ein Jahr in einem deutschen Schutzgebiet oder aber drei Jahre in anderen tropischen- oder subtropischen Gebieten tätig gewesen war. Mit einem Höchstalter von 6o Jahren war diese Regelung noch deutlich nachgiebiger gewesen als ihr späteres Pendant. Darüber hinaus enthielt diese Maßgabe noch einen Vermerk, der sich speziell an die erfahrenen Kolonialbeamten der Kaiserzeit wandte: „Die älteren Jahrgänge werden in den Schutzgebieten voraussichtlich nur für eine beschränkte Übergangszeit beschäftigt werden“, ${ }^{194}$ um der ,jungen Ingenieursgeneration nur noch als willkommene Berater zur Seite“ zu stehen, ${ }^{195}$ denn, wie Remy an anderer Stelle betonte, ,[d]ie Erfahrungen einer technischen Pioniergeneration dürfen nicht verlorengehen."196

Fehlende Kolonialerfahrung konnte aber auch in diesen Richtlinien durch Jugend substituiert werden, so wurden Nichtkolonialkenner bis zu einem Alter von 35 Jahren zugelassen, wobei hier der staatliche oder kommunale Parteidienst mit einem Wert von fünf Jahren angerechnet wurde. Zusätzlich mussten die Bewerber tropentauglich sowie „politisch einwandfrei“ sein. ${ }^{197}$ Der Umstand, dass Mitglieder der NSDAP noch im Alter von 40 Jahren als potenzielle Kolonialbeamte zugelassen waren, lässt darauf schließen, dass eine Tätigkeit als Kolonialingenieur sowohl als ehrenhaft als auch als begehrt eingeschätzt wurde, was eine dementsprechende Bevorzugung sinnvoll erscheinen lässt. Wäre die kolonialtechnische Arbeit als Bestrafung oder als einem Ingenieur unwürdig betrachtet worden, hätte eine solche Regelung ihrem Sinn entbehrt. Vielmehr ist davon auszugehen, dass nicht erst mit

\footnotetext{
192 Remy, Zukunft des Schienenweges, 1937, S. 729.

193 Bewerber staatlicher Kolonialdienst, um 1940, BArchB, NS 14/24.

194 Ebda.

195 Remy, Zukunft des Schienenweges, 1937, S. 729.

196 Remy, Verkehrspolitik, 1937, S. 457.

197 Bewerber staatlicher Kolonialdienst, um 1940, BArchB, NS 14/24.
} 
der Machtübernahme durch die Nationalsozialisten die Arbeit in Afrika und damit jenseits dessen, was als technische Zivilisation begriffen wurde, einen besonderen Reiz ausübte - gerade für die technische Profession. ${ }^{198}$

Ist es durchaus legitim, für das Deutsche Reich von einer verstärkten Wahrnehmung des Problems der Ausbildung von Kolonialingenieuren zu sprechen, so erscheinen die benannten Versuche im Vergleich zum britischen Vorgehen marginal. Um den Bedarf an qualifizierten Ingenieuren für die Arbeit im britischen Kolonialreich besonders in Südostasien zu decken, wurde 1870 in Coopers Hill eigens das Royal Indian Engineering College eröffnet. Anders als der Name vermuten lässt, wurden die Absolventen des dreijährigen Studiums hiernach zwar vor allem in Indien eingesetzt, fanden bis zur Schließung der Einrichtung 1906 aber auch zunehmend in anderen Gebieten des Britischen Empires Beschäftigung. ${ }^{199}$ In Indien selbst hatten die Briten jedoch bereits mehr als 20 Jahre zuvor mit dem Engineering College in Roorkee einen Schritt in Richtung der institutionalisierten schulischen Ausbildung von Ingenieuren unternommen, wie sie im zeitgenössischen England nicht durchsetzbar gewesen wäre. ${ }^{200}$ Die vier Colleges, die die Kolonialmacht bis in die 186oerJahre in Indien eröffnete, waren mit dem Ziel eingerichtet worden, den Bedarf des Departements für Öffentliche Arbeiten mit lokalen Arbeitskräften kostengünstig zu decken. ${ }^{201}$

\subsubsection{Das Ende kolonialer Träume}

Das Ende dieser Phase „der Kolonialeuphorie der 1940er Jahre“ läuteten die deutschen Niederlagen bei Kursk und Stalingrad 1943 ein, die auch die Aufgabe jeglicher kolonialer Zielstellungen zur Folge hatten. ${ }^{202}$ Von Epp, der noch im besagten Jahr 1943 überzeugt von der Bedeutung der kolonialen Propaganda und der Arbeit des KPA war, sah sich dennoch den zunehmenden Einschränkungen und schließlich der Beendigung jeglicher Arbeit der staatlichen Kolonialverbände hilflos gegenüber. ${ }^{203}$ Diese finale Entwicklung bestätigt auch ein Blick auf die entsprechenden Veröffentlichungen.

Karl Krüger hatte noch 1939 in Zusammenarbeit mit dem Technischen Ausschuss des KWK in Berlin begonnen, die Schriftenreihe Kolonial- und Tropentechnik herauszugeben. Die erste Publikation der Reihe zum übergreifenden

\footnotetext{
198 Vgl. Roß, Erlebnisse, 1941, S. 54 f.

199 Buchanan, Diaspora, 1986, S. 517.

200 Kumar, Colonial Requirements, 1995, S. 216.

201 Ebda., S. 217-219.

202 Linne, Aufstieg und Fall, 2003, S. 276.

203 Vgl. Linne, Deutschland jenseits, 2008, S. 151-159; Hildebrand, Reich zum Weltreich, 1969, S. 416 .
} 
Themenkomplex der Tropentechnik stammte ebenfalls aus seiner Feder. ${ }^{204}$ Geplant war die Herausgabe von neun weiteren Bänden verschiedener Autoren zu ähnlichen Bereichen in kurzen Zeitabständen. Infolge des Krieges schob man die Publikation der Reihe jedoch weiter auf, sodass 1942 lediglich der Reichsbahndirektionspräsident Ernst Randzio zusammen mit Karl Remy seine Monografie über den kolonialen Bahnbau publizierte. Die Veröffentlichung des von Karl Krüger herausgegebenen Taschenbuchs des Kolonialingenieurs wurde demgegenüber in Gänze ad acta gelegt. ${ }^{205}$

Diese Entwicklung betraf natürlich auch die kolonialtechnischen Erschließungspläne. Symbolisch für das Ende der aktiven kolonialtechnischen Bestrebungen steht Remys Zusammenfassung der wichtigsten Erkenntnisse der Abteilung IV „Verkehr und Technik“vom Beginn ihrer Tätigkeit bis zur Stilllegung im Februar 1943 als Abschlussbericht des KPA. ${ }^{206}$ Der gut 8 o Seiten umfassende Bericht bediente sich bestehender Muster und Argumentationslinien, die sich auch in den Jahren zuvor immer wieder in der kolonialtechnischen Literatur fanden. Neben dem Vorwurf unzureichender Investitionen und Anstrengungen der Kolonialmächte England und Frankreich hinsichtlich des Ausbaus der kolonialen Infrastruktur wurde auf den immer noch unbefriedigenden Bestand an geeignetem Kartenmaterial verwiesen. Die besonderen Bedingungen in den Kolonien selbst, die den Bau von Brücken ausschließlich mit genormten, aus Europa importierten Teilen möglich machten, und der relativen Leere Afrikas, weshalb der Grunderwerb für den Bahnbau um ein Vielfaches günstiger sei als in Europa, samt der Behauptung, dass Afrika selbst einen Wert lediglich als „wirtschaftlicher Ergänzungsraum zu Europa“ besäße, fanden sich auch in Remys Bericht wieder. ${ }^{207}$

Es entbehrt nicht einer gewissen Ironie, wenn Remy in seinem Abschlussbericht zu einer ganz ähnlichen Beurteilung der afrikanischen Verhältnisse kam wie schon die ersten deutschen Kolonialingenieure mehr als 30 Jahre zuvor. Unbewusst, davon ist zumindest auszugehen, stellte er diesen ein Armutszeugnis über das von ihnen Erreichte aus, wenn er in seinem Zwischenfazit

\footnotetext{
204 Krüger, Tropentechnik, 1939.

205 Randzio/Remy, Kolonialbahnbau, 1942; vgl. darin auch das Vorwort von Karl Krüger (S. 5). Durchaus zutreffend charakterisiert Linne die Zeit zwischen Juli 1940 und Dezember 1941 als das „lange[] Jahr der Kolonialeuphorie“: Linne, Deutschland jenseits, 2008, S. 81.

206 Remy, Zusammenfassung Abteilung „Verkehr und Technik“, 1.3.1943, BArchB, NS 52/101; Zeitgleich wurde auch die Herausgabe der Zeitschrift Der Deutsche Auslandsingenieur eingestellt, die letzte regelmäßige Publikation, in der kolonialtechnische Themen behandelt wurden.

207 U. a. Schubert, Rettung Europas, 1929; Remy, Zusammenfassung Abteilung „Verkehr und Technik“, 1.3.1943, BArchB, NS 52/101, S. 1-3, 6 f., 22, 24.
} 
konstatierte: „Die kolonialen Gebiete sind Neuland und bisher durch Verkehrsmittel noch wenig erschlossen.“208 Ein Satz, der, losgelöst von seinem archivalischen und historischen Kontext, in dieser Form auch am Beginn der deutschen Kolonialherrschaft gestanden haben könnte. ${ }^{209}$ Die Tatsache, dass Remy dieses Resümee jedoch 1943 zog, gibt der Kolonialtechnik, ihren Akteuren und ihren Manifestationen in Form von Eisenbahnen und Straßen den faden Beigeschmack der Bedeutungslosigkeit. Liest man den Bericht zwischen den Zeilen, so entsteht der Eindruck, dass auch die koloniale Technik samt ihren Akteuren nichts an den Zuständen und Herausforderungen in den ehemaligen deutschen Kolonien geändert habe. Somit hätten auch die Ingenieure und Techniker in den ehemaligen Schutzgebieten ihr eigentliches Ziel verfehlt.

Akteure wie Karl Krüger, der zu jung war, um selbst in den deutschen Kolonien gearbeitet zu haben, verwiesen jedoch noch auf einen anderen Zusammenhang. ${ }^{210}$ Ideen und Vorstellungen der Kolonialtechnik ließen sich ohne Weiteres auch nach dem Zweiten Weltkrieg propagieren und fanden Eingang in die Vorstellungswelt der späteren Entwicklungshilfe. ${ }^{211}$

\subsection{Postkoloniale Karrieren}

Die mit der Gründung der AKOTECH bis zu ihrer Vereinigung mit der ADA eng verknüpfte Biografie des ehemaligen Kolonialingenieurs Alfred Andreas Schubert stellt lediglich einen einzelnen Lebensweg dar, der sich eng mit dem Streben nach Institutionalisierung der eigenen Profession verband. Es werden im Folgenden drei weitere Lebensläufe von Kolonialingenieuren ausgeführt und analysiert. Dabei wird beispielhaft herausgearbeitet, dass Diplom-Ingenieure und Regierungsbaumeister mit kolonialer Erfahrung nach ihrer Rückkehr ins Deutsche Reich erfolgreich in prestigeträchtige Positionen aufrücken konnten. Der Fokus wird dabei auf jenen Personen liegen, die zuvor bei einem deutschen Gouvernement in Afrika beschäftigt gewesen waren. Gleichzeitig werden jene Ingenieure dabei ausgespart, die im Zuge der Diamantenfunde in DSWA durch glückliche Umstände und Investitionen, die nicht spezifisch an ihre technische Vorbildung gebunden waren, teils enorme Vermögen anhäufen konnten. Ebenso wenig wird detailliert auf jene

208 Remy, Zusammenfassung Abteilung „Verkehr und Technik“, 1.3.1943, BArchB, NS 52/101, S. 21.

209 Vgl. u. a. Hake, Eisenbahnbau in Deutsch-Ostafrika (2), 1889.

210 Vgl. zu Krüger v. a. van Laak, Imperiale Infrastruktur, 2004, S. 393-402.

211 Vgl. dazu u. a. Krüger, Technik für alle Länder, 1959; Krüger, Regionaltechnik, 1961; Krüger, Ingenieure bauen, 1969; dazu auch van Laak, Imperiale Infrastruktur, 2004, S. 393-402. 
Akteure eingegangen, die aufgrund ihrer Staatsbürgerschaft auch nach dem Krieg in Afrika tätig bleiben konnten wie der Ingenieur Clemens Gillman. ${ }^{212}$ Dank seiner elterlichen Verbindung nach Deutschland und England sowie seiner Ausbildung in der Schweiz war er nicht nur, wie zuvor beschrieben, an leitender Stelle für Philipp Holzmann in Afrika tätig, sondern stieg nach dem Ersten Weltkrieg im Kontext der englischen Mandatsherrschaft sogar zum Chefingenieur der Tanganjika-Bahn auf. ${ }^{213}$

\subsubsection{Karl Rintelen (1875-1961)}

Anlässlich seines 8o. Geburtstages erschien im Sommer des Jahres 1955 in Glasers Annalen ein Artikel über das Leben des Abteilungspräsidenten a.D. Rintelen. Erwartet man von dem kurzen Abschnitt umfassende Bezüge auf seine kolonialen Erlebnisse in Afrika und später in Ecuador, so wird man auf ganzer Linie enttäuscht. Dem nicht benannten Autor waren diese Abschnitte im Leben Karl Rintelens nur wenige Sätze wert. ${ }^{214}$ Ist dieser Umstand auf fehlende Kenntnisse seiner Tätigkeit in der deutschen Kolonie DSWA zurückzuführen, so mindert dies jedoch keinesfalls die Bedeutung seiner fast sechsjährigen Tätigkeit in Afrika zwischen Oktober 1907 und März 1913 als Kolonialingenieur und Eisenbahnkommissar. ${ }^{215}$

Noch vor Ausbruch des Ersten Weltkrieges wechselte Rintelen aus dem deutschen in den ecuadorianischen Staatsdienst. Dank der Beurlaubung von seinem Amt als Vorstand des Königlichen Eisenbahn-Werkstättenamtes Stendal 1914 konnte er eine Stellung als Berater und Gutachter des Eisenbahnwesens beim Ministerium des Inneren der Republik Ecuador antreten. Die nun in seinen Tätigkeitsbereich gehörenden Eisenbahnen beschrieb man in Glasers Annalen als die anspruchsvollsten der Welt und führte seine Ernennung auf "[s]eine vieljährige Erfahrung im kolonialen Eisenbahnwesen“ zurück. ${ }^{216}$ Als „Generaldirektor für Öffentliche Arbeiten“, zu dem er aufstieg, zog er im Laufe des Krieges auch internationale Aufmerksamkeit auf sich. ${ }^{217}$ Seit 1920 lehrte er als Professor an der hiesigen Universität von Quito über elektrische

212 Zu nennen wäre in diesem Zusammenhang auch noch der bereits im Rahmen dieser Arbeit angeführte Schweizer Diplom-Ingenieur Leon Kooyker.

213 Weigt, Clemens Gillman, 1949, S. 193 f.; vgl. zu seiner Biografie Hoyle, Pioneer Geographer, 1896; Hoyle, Life and Work, 1987.

214 Vgl. Anonymus, Abteilungspräsident, 1955.

215 Vgl. RKA an Gouvernement (DSWA), 4.3.1910, BArchB, R 1002/1396, fol. 51; RKA an Gouvernement (DSWA), 2.4.1913, ebda., fol. 114 .

216 Anonymus, Berufung des Regierungsbaumeisters, 1914; vgl. hierzu auch die Aussagen zu Dorpmüller: Gottwaldt, Reichsverkehrsminister, 2004, S. 145 .

217 Die Bezeichnung seines Anstellungsverhältnisses wird an anderer Stelle treffender als technischer Berater des Ministeriums für Öffentliche Arbeiten („Asesor Técnico del 
Traktion und Eisenbahnbau. Jene Institution verlieh ihm nur wenige Jahre vor seinem 8o. Geburtstag die Würde eines Ehrenprofessors der physikalischmathematischen Universität. 218

Rintelens koloniale Erfahrungen und sein dementsprechend geprägtes Denken wurden besonders bei seiner Antrittsrede als Professor an der Universität in Quito deutlich. Mit Blick auf Ecuador sprach er auch hier von „Erschließungsbahnen“, die in finanzieller Hinsicht anders zu bewerten seien, als dies bei Bahnen in hochtechnisierten Ländern der Fall sei. ${ }^{219}$ Wie in den deutschen Kolonien in Afrika galt es auch hier, einen Ausgleich zwischen Investitionen auf der einen Seite und den dadurch beeinflussten Betriebskosten auf der anderen Seite zu finden. Letztlich verband sich mit diesem Problem die Frage, welche Investitionen eine bestimmte Senkung der dauernden Betriebskosten rechtfertigen würden, wobei er solche Bahnen gemäß ihren kolonialen Pendants nicht auf ihren rein ökonomischen Nutzen reduziert wissen wollte. ${ }^{220}$

Nach seiner Rückkehr in den deutschen Staatsdienst engagierte er sich nicht nur im RDT sondern später auch bei der AKOTECH und war bis 1930 Abteilungsleiter der Reichsbahndirektion Königsberg, bevor er in gleicher Stellung nach Breslau wechselte. ${ }^{221}$ Darüber hinaus erfahren wir vom Verfasser des Artikels zu seinem 80. Geburtstag, dass Rintelen eine "aussichtsreiche“ Karriere bevorstand, die jedoch 1936 - aus politischen Gründen, wie der Autor vermutet - ein jähes Ende fand.222 Es ist durchaus möglich, dass er sich ähnlich wie Julius Dorpmüller, der fast 20 Jahre die Stelle als Generaldirektor der Reichsbahn bekleidete, mit Vorwürfen über Kontakte ins Ausland konfrontiert sah, die bei Dorpmüller auf dessen Tätigkeit in China zurückgingen. ${ }^{223} \mathrm{Ob}$ ähnliche Kontakte für Rintelen zum Problem wurden, lässt sich jedoch nicht belegen.

Dieser historische Abriss macht deutlich, dass eine vormalige Beschäftigung in den Kolonien, wie im Fall Rintelens, einen Aufstieg in der Bürokratie der Eisenbahnverwaltung mitnichten behinderte. Vielmehr waren gerade diese Erfahrungen entscheidend für seine Anstellung als Bevollmächtigter für Öffentliche Arbeiten in Ecuador. Speziell seine Zeit in Afrika und die

Ministerio de Obras Públicas“) ausgeführt: Mensaje del Presidente de la República al Congreso Ordinario de 1914, Quito, S. 43; Anonymus, Guayaquil and Quito, 1917.

218 Anonymus, Abteilungspräsident, 1955.

219 Rintelen, Wirtschaftlichkeit im Eisenbahnbau, 1920.

220 Rintelen, Gradiente Económica, 1916.

221 Anonymus, Oberbaurat Rintelen, 1924; Anonymus, Personal-Nachrichten, 1930.

222 Anonymus, Abteilungspräsident, 1955.

223 Gottwaldt, Reichsverkehrsminister, 2004, S. 143, 146 f. 
spezifischen dort erlangten Kenntnisse ließen ihn für den südamerikanischen Staat interessant erscheinen. Treten auch gewisse Parallelen zwischen kolonialem Denken und Handeln, vor allem auch auf der begrifflichen Ebene, deutlich hervor, so trifft dieser Umstand nicht auf alle Kolonialingenieure zu. Karl Rintelens Biografie mag für diese Parallelisierung sprechen, etwas anders verhält es sich jedoch mit Hermann Rukwied.

\subsubsection{Hermann Rukwied (geb. 1879)}

Es ist davon auszugehen, dass sich Hermann Rukwied und Karl Rintelen persönlich kannten. Beide lebten und arbeiteten nicht nur über Jahre gemeinsam in DSWA -Rukwied arbeitete zwischen 1906 und 1910 in leitender Stellung beim Kolonialbahnbau -, sie engagierten sich auch nach dem Kriegsende für die AKOTECH. Dank seiner Personalakte sind über Rukwieds Handeln und Leben in den 193oer-, 4oer- und 5oer-Jahren deutlich mehr Informationen verfügbar als über die meisten anderen Kolonialingenieure. Seine Vita bietet daher einen besonders wertvollen Einblick in die berufliche Entwicklung unter dem nationalsozialistischen Regime. Neben den Personalakten aus der Zeit beim RKA existieren im Landeshauptarchiv in Stuttgart auch Archivalien, die darüber Auskunft geben, welcher Tätigkeit er bis $195^{\circ}$ nachging. Ferner lag das Urteil der zuständigen Spruchkammer aus dem Jahre 1948 über seine Stellung bis zum Ende des Zweiten Weltkrieges vor.

Nach dem Ende seiner vierjährigen Beurlaubung zum Kolonialdienst war Regierungsbaumeister Rukwied im November 1910 als Abteilungsingenieur planmäßig bei der Württembergischen Staatseisenbahnverwaltung eingestellt worden. Im Rahmen dieser Stellung verbrachte er den Ersten Weltkrieg als Feldeisenbahner an der Westfront. ${ }^{224}$ In der Weimarer Republik war Rukwied ab 1919 als Vorstand der Eisenbahnbauinspektion in Sigmaringen tätig, bis er 1923 nach Stuttgart wechselte, um hier als Vorstand der Eisenbahnsektion an der Fertigstellung des Hauptbahnhofes mitzuwirken. Bevor Rukwied 1934 als Leiter der Obersten Bauleitung in Halle zu den Reichsautobahnen abberufen wurde, übernahm er die Leitung des Reichsbahn-Betriebsamtes in Ulm. ${ }^{225}$

Über den Vorfall, der ihn seine Stellung in Ulm kostete, durch einen glücklichenZufalljedoch die Umsiedlungnach Halle ermöglichte, berichteteRukwied vor der Spruchkammer, die 1948 sein Verhältnis zum nationalsozialistischen

224 Vgl. für Rukwieds Schilderungen seiner Erlebnisse während des Ersten Weltkrieges: Rukwied, Erinnerungen, 1969, S. 37-43.

225 Personalangaben Rukwied, 27.5.1947, HStAS, EA 2/15o Bü 1403; ebda., S. 44. Als Leiter wurden vor allem Reichsbahn-Oberräte im Alter von ca. 5o Jahren eingestellt: Rukwied, Erinnerungen, 1969, S. 46. 
Regime klären sollte, ausführlich. Aufgrund einer Auseinandersetzung mit einem ihm unterstellten Bahnarbeiter geriet er bereits 1933 in Schwierigkeiten. Da es sich bei dem Arbeiter um ein frühes NSDAP-Mitglied handelte, ließ ihm der verantwortliche Polizeipräsident, Wilhelm Dreher, eine „hochnotpeinliche Untersuchung" angedeihen. Auch über dessen Aufstieg vom Fabrikschlosser zum Polizeipräsidenten verlor Rukwied in der Rückschau kein gutes Wort. ${ }^{226}$ Darüber hinaus führte er in der Befragung einen Zeitungsartikel zu seinen Gunsten an, in dem er scharf angegriffen wurde als „einer, der den Zug der Zeit noch nicht erfasst hat“. 227 Die Spruchkammer, die ihn 1948 als „Mitläufer“ einstufte, unterstellte Rukwied nach diesem Vorfall einen "Gesinnungswechsel [..], da er sich nach dieser Versetzung als Parteianwärter anmeldete“..228

Über seine Tätigkeit beim Autobahnbau wissen wir dank Rukwieds Ausführungen in seinen Erinnerungen, dass er an der Errichtung von mehr als 1.ooo Straßenkilometern bei der Bauleitung in Halle und später in Linz beteiligt gewesen war. ${ }^{229}$ Interessanterweise findet sich mit Reichsbahndirektor Oswald Reinhardt ein weiterer Kolonialingenieur in übergeordneter Position, bei der Direktion verantwortlich für „Entwurf, Bau- und Ausgestaltung der Reichsautobahnen, technische Fragen, Vergebung (Referat T)“. ${ }^{230}$ Nicht nur die beiden Regierungsbaumeister, die bereits in DSWA zusammengearbeitet hatten, gelangten an hochrangige Leitungsfunktionen bei der Reichsautobahn, auch anhand anderer Beispiele zeigen sich gewisse Überschneidungen von Kolonial- und Autobahnbau. Bei einem der sechs Verwaltungsratsmitglieder der Direktion der Reichsautobahnen, August Goetz, handelte es sich beispielsweise um den Direktor der Otavi-Minen- und Eisenbahngesellschaft in Berlin. ${ }^{231}$

Ende der 3oer-Jahre bezog sich Karl Krüger auf den eben benannten Zusammenhang. Er, der zwar AKOTECH-Mitglied war, jedoch nicht über eigene Kolonialerfahrungen verfügte, bewertete beide Bereiche auf strategischer Ebene ganz ähnlich. Für Krüger dienten die Autobahnen daher als eine Art Bewährungsprobe für eine zukünftige Arbeit in den Kolonien. „Die Planung unserer Reichsautobahnen hat gezeigt, daß unsere Ingenieure auf

226 Erklärung Reichsbahndirektionspräsidenten Siegel, 12.11.1946, HStAS, EA 2/15o Bü 1403, fol. 31; Rukwied, Erinnerungen, 1969, S. 44.

227 Abschrift „Ulmer Sturm“, Nr. 74 (29.3.1933), 22.2.1946, ebda.

228 Urteilsbegründung der Spruchkammer, Rukwied, 1.3.1948, ebda., fol. 12.

229 Rukwied, Erinnerungen, 1969, S. 45-82; Rukwied, Reichsautobahn, 1936, S. 233 f.

230 Volk, Gesellschaft Reichsautobahnen, 1935, S. 30; Graf an Reinhardt, 4.7.1939, Universitätsarchiv-Stuttgart, Forschungs- und Materialprüfungsanstalt für das Bauwesen Otto-Graf-Institut 33/1/1413.

231 Ebda. 
diesem Gebiet Außerordentliches zu leisten vermögen.“232 Ein weiteres Indiz für diese These stellte die Anfrage des Kolonialingenieurs Carl Neumann dar, der vor seiner Anstellung beim Gouvernement in DSWA mehr als sechs Jahre für Lenz \& Co in Afrika verbracht hatte. Neumann bat 1934 um die Heraussendung seiner Unterlagen über den staatlichen Kolonialdienst, da ihm diese bei einem „Raubüberfall“ zwei Jahre zuvor in Persien gestohlen worden waren, um sich damit auf eine Stelle bei der Reichsautobahn zu bewerben. ${ }^{233}$

Im Gegensatz zu der im zweiten Kapitel angeführten unpolitischen Selbsteinschätzung der Profession der Techniker war Hermann Rukwied aktives Mitglied der Deutschen Demokratischen Partei. ${ }^{234}$ Mit dieser Tatsache im Zusammenspiel mit dem Umstand, dass er in den 1920er-Jahren sogar den regionalen Vorsitz der Partei führte, versuchte sich der Regierungsbaumeister vor der Spruchkammer selbst zu entlasten. Die Abkehr von seiner einst national-liberalen politischen Einstellung und den Eintritt in die Deutsche Demokratische Partei erklärt er mit der Erfahrung des Weltkrieges und der Weigerung der Nationalliberalen im preußischen Abgeordnetenhaus, das Dreiklassenwahlrecht abzuschaffen, was er als eine nicht hinnehmbare Entrechtung der Masse der kämpfenden Soldaten missbilligte. ${ }^{235}$ Dementsprechend betonte Rukwied hinsichtlich seiner Mitarbeit in Führungspositionen während der Zeit des Nationalsozialismus, er sei „im Herzen immer Demokrat geblieben“.236

Zwar bezog auch die Stuttgarter Spruchkammer, die 1922 von Rukwied im Rahmen seiner Parteiarbeit geäußerte Kritik an antisemitischen Vorstellungen mit ein, ebenso wie sie ihm konstatierten, „innerhalb seines Amtes sich niemals als Nationalsozialist aufgeführt“ zu haben, dennoch sei er "aus irgendeinem Grund bevorzugt in die NSDAP aufgenommen" worden. Letztlich war für ihre Entscheidung, ihn als Mitläufer einzustufen, ausschlaggebend, dass er „seine Intelligenz als Aushängeschild der NSDAP zur Verfügung“ gestellt habe und schließlich während des Krieges an führender Stelle Bauvorhaben beim Ministerium für Bewaffnung und Munition betreute und nach 1943 als Baubevollmächtigter beziehungsweise Leiter der Wohnraumbewirtschaftungsstelle für das Protektorat (Dienststelle Prag) tätig gewesen war. ${ }^{237}$ Einer Argumentation über die „Wertneutralität der Technik“, wie sie vonseiten

\footnotetext{
232 Krüger, Technische Erschließung, 1938, S. 2.

233 Neumann an AA, 11.6.1934, BArchB, R 1002/1249.

234 Vgl. auch Manegold, Emanzipation der Technik, 1977, S. 35.

235 Rukwied, Erinnerungen, 1969, S. 43 f.

236 Meldebogen Befreiung vom Nationalsozialismus, 5.6.1947, HStAS, EA 2/15o Bü 1403, fol. 4; Abschrift: Hohenzollerische Blätter, Hechinger Tagblatt (22.5.1922), vgl. ebda., fol. 3 .

237 Urteilsbegründung Spruchkammer zu Rukwied, 1.3.1948, ebda., fol. 12.
} 
der Techniker und Ingenieure im 20. Jahrhundert immer wieder beschworen wurde, entzog die Spruchkammer damit von Beginn an jegliche Grundlage. ${ }^{238}$

\subsubsection{Franz Allmaras (1875-1953)}

Der folgende Abschnitt über den Kolonialingenieur Franz Allmaras ist bewusst kurz gehalten, da Ausführungen zu seiner biografischen Entwicklung bereits in den entsprechenden Kapiteln enthalten sind, vor allem zu seiner Rolle in der kolonialrevisionistischen Bewegung unter Führung des KPA. Lediglich die Art und Weise, wie es Allmaras gelang, aus seinen afrikanischen Erfahrungen Kapital zu schlagen, wird vertieft werden.

Nach dem Ersten Weltkrieg und dem Ende seiner erfolgversprechenden Karriere im ostafrikanischen Kolonialdienst war Allmaras wie so viele andere Kolonialbeamte zuerst beim Ministerium für Wiederaufbau beschäftigt, bevor er seine Beratungstätigkeit für die deutsche Regierung in Südamerika aufnahm und durch Reichspräsident Friedrich Ebert zum Ministerialrat ernannt wurde. Auch die Firma Lenz \& Co, die ihm noch aus seiner Zeit in DOA bekannt war, beauftragte ihn mit der Überwachung technischer Großprojekte in Südamerika, wobei er ebenso die Möglichkeiten deutscher Beteiligungen eruieren sollte. ${ }^{239}$

Wenige Jahre später bewarb sich Allmaras um eine Anstellung in Persien, wo auch der Kolonialtechniker Karl Neumann 1932 untergekommen war. $^{240}$ In einem hierfür ausgestellten Empfehlungsschreiben attestierte ihm der ehemalige Gouverneur von DOA, Heinrich Schnee, ein "ausserordentlich grosses Organisationstalent" und erklärte ihn "nach seinem Charakter wie nach seinen Fähigkeiten für sehr geeignet“, verschiedenste Leitungsfunktionen „in fremden Ländern" zu übernehmen. ${ }^{241}$ Aufgrund ihrer Zeit in Ostafrika waren sich die beiden auch persönlich bekannt. Nachdem der Versuch einer Anstellung in Persien gescheitert war, zeigte sich Allmaras zwischen 1931 bis 1937 für den

238 Lorenz/Meyer, Einführung, 2004, S. 3 f.

239 Lenz \& Co an AA, 23.11.1928, PA AA, R 91650; Allmaras, Bahn Arica-La Paz, 9.11.1928, ebda.; Verband Alter Münchener Germanen, Gedenkblätter, 2013, S. 20-23; Allmaras verhandelte im Geheimen sowohl mit argentinischen, bolivianischen als auch chilenischen Vertretern: vgl. Lenz \& Co an AA, 1.6.1929, PA AA, R 9165o.

240 Neumann an AA, 11.6.1934, BArchB, R 1002/1249; Allmaras' Beschäftigung mit dem Thema wurde auch an einer von ihm $193^{2}$ in der Kolonialen Rundschau veröffentlichten Rezension deutlich: Allmaras, Buchbesprechung, $193^{2}$.

241 Schnee, Empfehlungsschreiben Allmaras, 31.12.1930, GStA PK, VI. HA. NL Schnee, Nr. 29, fol. 77; Allmaras an Schnee, 28.12.1930, ebda., fol. 76; Schnee an Groppe, 31.12.1930, ebda., fol. 77. Die Tatsache, dass Allmaras von 1931 bis 1937 den Bau der Kalmitstraße in seinem Heimatort Maikammer leitete, lässt den Schluss zu, dass seine Bemühungen um eine Anstellung in Persien erfolglos blieben. 
Bau der Kalmitstraße in der Umgebung seines Heimatortes Maikammer verantwortlich, wobei es sich hierbei vor allem um ein Projekt der staatlichen Wohlfahrt handelte. ${ }^{242}$

Beide Beschäftigungsverhältnisse, sowohl von Allmaras als auch von Rintelen, lassen einen Übergang von der Perspektive einer klassischen Kolonialtechnik hin zu einer vor allem auf Exportsteigerung ausgerichteten Auslandstechnik konstatieren, in deren Sinne Rintelens Tätigkeit auch hinsichtlich der Möglichkeit bewertet wurde, dass sie zu möglichen Ausführungen und industrieller Zusammenarbeit mit dem entsprechenden südamerikanischen Land führen könne. ${ }^{243}$

242 Allmaras, Kalmitstraße, 1931, S. 4.

243 Anonymus, Berufung des Regierungsbaumeisters, 1914. 